\title{
Dynamic monitoring of a stadium suspension roof: Wind and temperature influence on modal parameters and structural response
}

\author{
Nuno Martins, Elsa Caetano*, Sandro Diord, Filipe Magalhães, Álvaro Cunha \\ ViBest, Faculty of Engineering, University of Porto, Rua Dr. Roberto Frias, s/n, 4200-465 Porto, Portugal
}

\section{A R T I C L E I N F O}

\section{Article history:}

Received 16 January 2013

Revised 10 October 2013

Accepted 12 October 2013

\section{Keywords:}

Suspension roof

Dynamic monitoring

Wind monitoring

Wind

Temperature

Modal variability

\begin{abstract}
A B S T R A C T
This paper describes an extensive experimental investigation conducted on the Braga Stadium suspension roof combining recent developments in terms of sensors, data communicating systems, computational power and automated output-only modal identification algorithms. The continuous monitoring program established around this outstanding structure has allowed the continuous measurement of wind, temperature and acceleration. The variation of such quantities during a period of 8 months has been investigated, with the purpose of obtaining a characterisation of the wind action based on field tests, establishing correlations with the structural response and finally analysing the influence of wind and temperature on the variation of modal parameters.
\end{abstract}

(c) 2013 Elsevier Ltd. All rights reserved.

\section{Introduction}

During the last decades, an enormous advance occurred in Wind Engineering leading to the development of complex models for the characterisation of wind and its effects on slender structures [1-8]. Such models have been founded on the results of scaled model wind tunnel tests, therefore incorporating several simplifications.

Recognising the importance of the developed formulations of wind analysis and of wind tunnels as fundamental tools for the design and research of complex structures [9-12], it is however noted that the consequences of the adopted simplifications on the dynamic behaviour of prototypes are very scarcely known, as it is very rare that instrumentation and accompanying of full scale behaviour under wind actions are implemented. Considering however the recent development in sensors and measurement systems and the increase in computational power, the rigorous characterisation of wind and of the dynamic behaviour of full scale structures becomes possible [13-16], leading to an improvement of analysis methods and allowing, for example, the replacement of typical formulations of analysis in the frequency domain by more powerful formulations in time which allow the consideration of nonlinear effects and therefore more accurately describe the dynamic behaviour of slender systems.

\footnotetext{
* Corresponding author. Tel.: +351 225081904.

E-mail address: ecaetano@fe.up.pt (E. Caetano).
}

On the other hand, during several decades, Experimental Dynamics was essentially used to identify the most relevant dynamic parameters of large civil structures at a certain stage of their lifetime, normally at the commissioning stage, with the main purpose of establishing correlations with numerical predictions or, in some cases, updating finite element models [17-19]. It was then considered that such tests could characterise the baseline condition of the structural behaviour, allowing subsequent detection of structural changes. Therefore, ambient vibration tests became gradually more common before and after rehabilitation works $[20,21]$, and even many research attempts have been conducted to detect early damage based on variations of modal parameters estimates, despite the adverse influence of several environmental factors [22-24].

However, the remarkable technological progress recently occurred in the field of data acquisition systems and information transmission through the Internet made feasible the continuous dynamic monitoring of the structural behaviour [25,26], which may complement other components of structural monitoring, such as the monitoring of loads (e.g. wind, traffic loads), static behaviour and durability [27]. Together with efficient software for monitoring data processing [28], these systems can presently play a very important role in the understanding of the structural behaviour either during the construction stage, or during the service lifetime, allowing in particular the automated extraction of accurate estimates of the structure modal parameters from continuously recorded responses during normal operation conditions, as well as the development of correlation analyses between the time 
evolution of environmental and operational factors (e.g. temperature, wind, traffic intensity) and modal properties [29].

In this context, this paper describes an extensive experimental investigation conducted on the Braga Stadium suspension roof with the purpose of accurately characterising the wind and temperature variations, and their influence on the variability of modal properties and structure response, based on adequate processing of continuous dynamic monitoring data collected during a period of 8 months.

\section{Description of the structure}

The subject matter of this study is the roof structure of the Braga Municipal Stadium, located in Braga, in the north-west of Portugal Fig. 1. This infrastructure was built for the 2004 European Football Championship that took place in Portugal. The stadium, designed by Eduardo Souto Moura in conjunction with the consultancy office Afassociados, has been considered by many a masterpiece of modern architecture [30].

The stadium was constructed on the mountainside of Monte Castro, where one of the tribunes was built into the hill itself, and the second was erected on the other side of the pitch. While the north-west side of the stadium is wide open to the valley, a great granite massif stretches along the south-east side (Figs. 1 and 2).

The highlight of the stadium is its suspension roof shown in Figs. 1 and 2. The roof is composed by 34 pairs of full locked coil cables with diameters varying between 80 and $86 \mathrm{~mm}$, spaced $3.75 \mathrm{~m}$ apart from each other. The cables span $202 \mathrm{~m}$ between the tops of both tribunes, supporting the two slabs on the first $57.3 \mathrm{~m}$ in each end, the central $88.4 \mathrm{~m}$ being free, as seen in Fig. 2. The slender concrete slabs, with only $0.245 \mathrm{~m}$ of thickness, are supported by the cables only in their normal direction, allowing for relative tangential movements between the two types of elements. A slight slope towards the south-east side is achieved by a variation of the cables length, which allows the efficient drainage of the rainwater. A transversal triangular truss is suspended from the inner border of each slab acting as a stiffness beam and simultaneously accommodating the floodlights and loudspeakers. The roof cables are anchored in two large beams at the top of both tribunes - east and west. The east tribune (seen on the left in Figs. 1(b) and 2) is structurally formed by $50 \mathrm{~m}$ high concrete walls, whose geometry was defined in order to minimise, at the level of the foundation, the unbalanced moments motivated by the combination of the gravitational action of the tribune and the high forces transmitted by the roof cables. In the west stand (seen on the right in Figs. 1(b) and 2 ), the concrete walls are anchored in the rock and the roof cable forces are transmitted to the foundation by prestressing tendons embedded in the concrete. The particular characteristics of the structure and the expected proneness to dynamic effects induced by the wind have motivated extensive studies developed during the design phase by various independent entities, with the purpose of adequately defining design loads and evaluating the corresponding static and dynamic behaviour [31-33]. The results provided by such studies as well as those obtained from numerical simulations and wind tunnel tests have demonstrated that the structure could be vulnerable to aeroelastic instabilities [34].

\section{Continuous monitoring of the roof structure}

The need of a strict control of the influence of environmental factors on the structural behaviour and geometry led to the installation of a static, dynamic and wind monitoring system during the construction of the structure [30]. The static monitoring system was essential during the construction and is based on a series of load cells installed in the cable anchorages, on embedded instrumentation of the concrete structure (strain gauges, tiltmeters and thermometers) and on instrumentation of the rock massifs and foundations with load cells installed in the anchors to the earth and in-place inclinometers. The dynamic monitoring system is important to observe the response of the roof to the wind excitation and is composed by 6 accelerometers, installed in the inner edges of the concrete slabs, and by cells to measure the wind pressure at various points on the underside and top of the roof slabs.

With the purpose of investigating the sensitivity of the structure to ambient effects and wind, ViBest/FEUP has installed two complementary monitoring systems on the west concrete slab: one to measure the dynamic response [35] and other to collect wind and temperature data [36]. The dynamic monitoring system has been active since March 2009 and has allowed the characterisation of the amplitudes of vibration of the slab, as well as the permanent identification of natural frequencies, modal shapes and modal damping ratios. The wind monitoring system was installed in December 2011, and is composed by two three-dimensional ultrasonic anemometers, suitable to measure wind velocities and directions, as well as sonic temperatures, at high sampling frequencies. The synchronisation of both measuring systems is enabled by accurate internal clocks set by GPS.

The installation of the two monitoring systems followed the layout represented in Fig. 3 [31,32].

\subsection{Dynamic monitoring system}

The dynamic monitoring system is essentially composed by six force balance accelerometers, a digitizer and a robust field processor. The six accelerometers are distributed on the top of the west slab according to the scheme shown in Fig. 3. The spatial distribution was defined with the goal of reasonably characterising at least the 10 first mode shapes identified in previous experimental and numerical works [37]. Two junction boxes group the signals of three sensors each in a single cable that is then linked to the
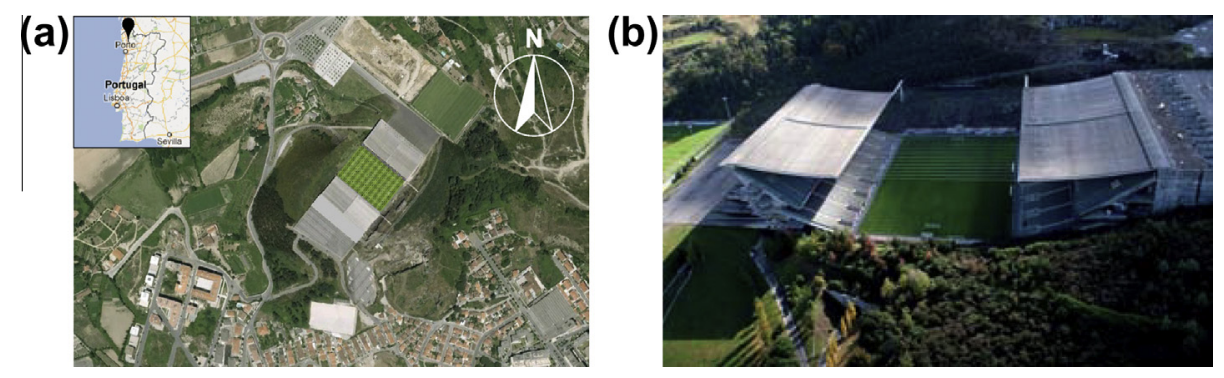

Fig. 1. (a) Top view and (b) perspective of the Braga Municipal Sports Stadium. 


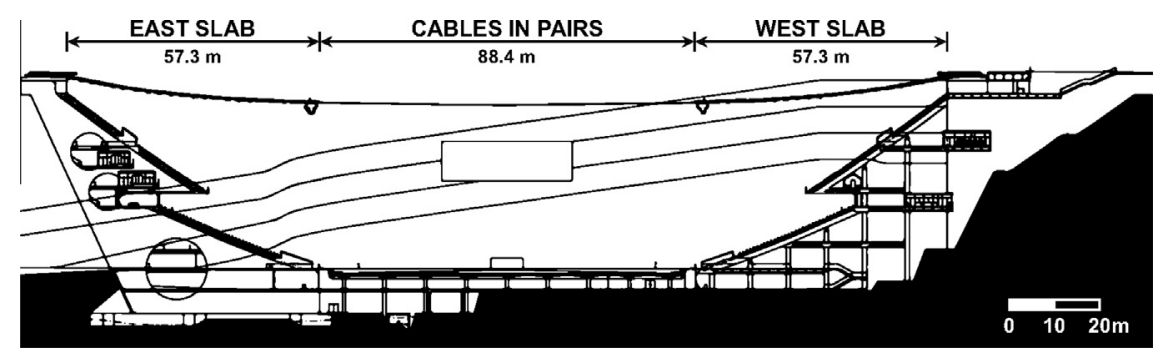

Fig. 2. Longitudinal section of the stadium suspension roof.
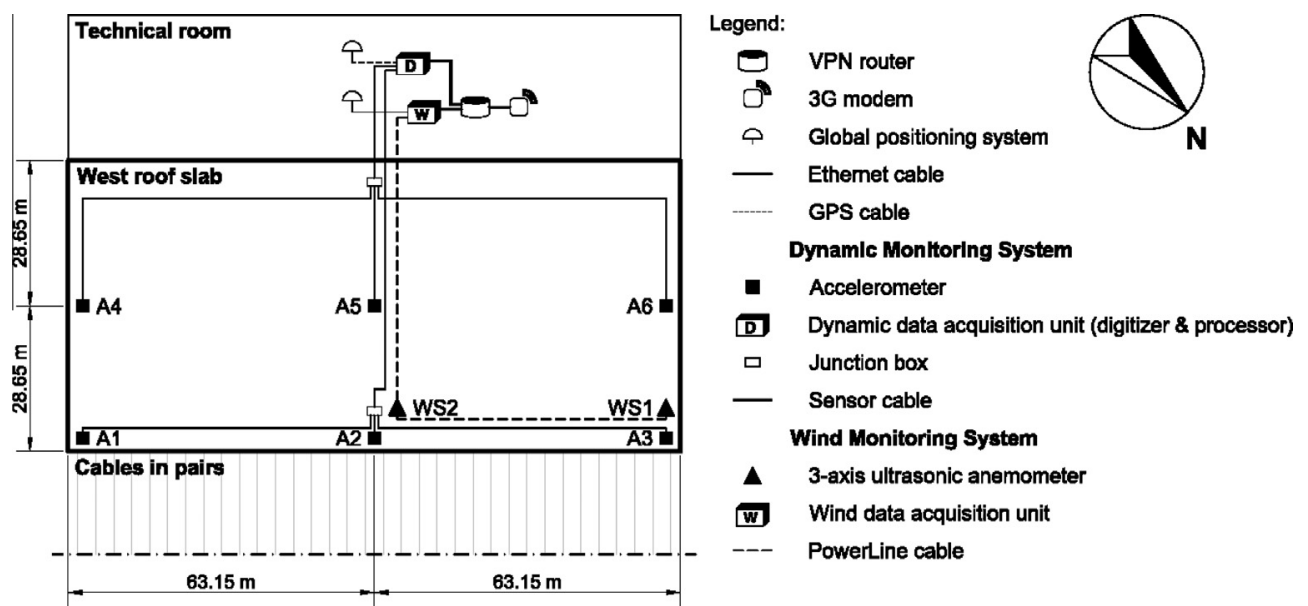

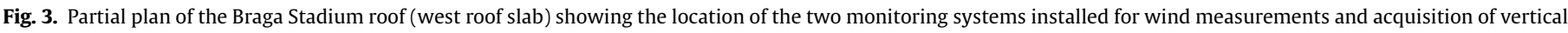
accelerations.

acquisition system. The acquired acceleration records are then transmitted to the field processor through an Ethernet cable.

The field processor organises the acceleration time series sampled at $20 \mathrm{~Hz}$ in consecutive text files with a time duration of $60 \mathrm{~min}$. The selection of this length for the time records resulted from a compromise between the goals of obtaining reliable estimates of modal damping ratios and a characterisation of the daily variations of the modal parameters [35].

\subsection{Wind measurement system}

This system comprehends two three-dimensional ultrasonic anemometers which allow the characterisation of the wind through time averaged statistics of speed, direction and incidence angles, spectra and co-spectra of velocity components and temperature. These quantities can be subsequently used to assess the influence of the wind loading on the dynamic behaviour of the roof structure. According to the scheme and picture presented in Fig. 3, the two anemometers were placed on the top of the west slab, both along its inner edge, WS1 in the northernmost point, and WS2 in the middle of the slab [36], just next to accelerometers A3 and A2 from the dynamic monitoring system, respectively. Both sensors are mounted on masts $3 \mathrm{~m}$ high in order to reduce the interferences from the structure with the flow. A sampling rate of $10 \mathrm{~Hz}$ was chosen in order to efficiently measure the turbulent component of the wind flow [38]. The collected wind time series are then stored in text files with a length of $10 \mathrm{~min}$.

\section{Field measurement of wind parameters}

The three-dimensional ultrasonic anemometers were configured to record the wind speed as three wind speed components, each along one of the sonic orthogonal axes $x, y$ or $z$. A coordinate rotation must be applied in order to obtain the mean wind speed, direction and elevation angles, as well as the turbulent component time series for the longitudinal, lateral and vertical directions. In this study, a double coordinate rotation scheme was used, described in some detail in $[38,39]$. According to this approach, the streamline referential is redefined every block-averaging period. The block time series are averaged, from which results a mean wind speed vector defined in the sonic coordinate system $x, y, z$ with sonic components $\left(\bar{u}_{m}, \bar{v}_{m}, \bar{w}_{m}\right)$. The objective of the double rotation method is to fix $\bar{v}=\bar{w}=0$, so that the total velocity vector is expressed by a streamline mean speed plus three orthogonal turbulent speed components $\left(\left(\bar{U}+u^{\prime}\right), v^{\prime}, w^{\prime}\right)$, a mean direction angle $(\gamma)$ and a mean elevation angle $(\beta)$.

The data presented herein corresponds to approximately 8 months of continuous measurements, between mid-December 2011 and the first days of August 2012.

\subsection{Mean wind speed, direction and elevation angles}

Fig. 4 shows the variation of the 10 -min mean wind speed measured by the two sonic anemometers since the installation of the wind measurement system. From this representation, one can verify that the evolution of the mean wind speed is generally coherent through the entire time between the two instruments, the values measured by WS1 being commonly higher. The observed mean wind speed shows maximum values of $9.37 \mathrm{~m} / \mathrm{s}$ and $7.22 \mathrm{~m} / \mathrm{s}$ for ultrasonic anemometers WS1 and WS2, respectively. Nevertheless, it is possible to conclude that the mean wind speed measured is generally low, with most of the measurements below $4 \mathrm{~m} / \mathrm{s}$. Henceforward just the data points with a significant wind speed 


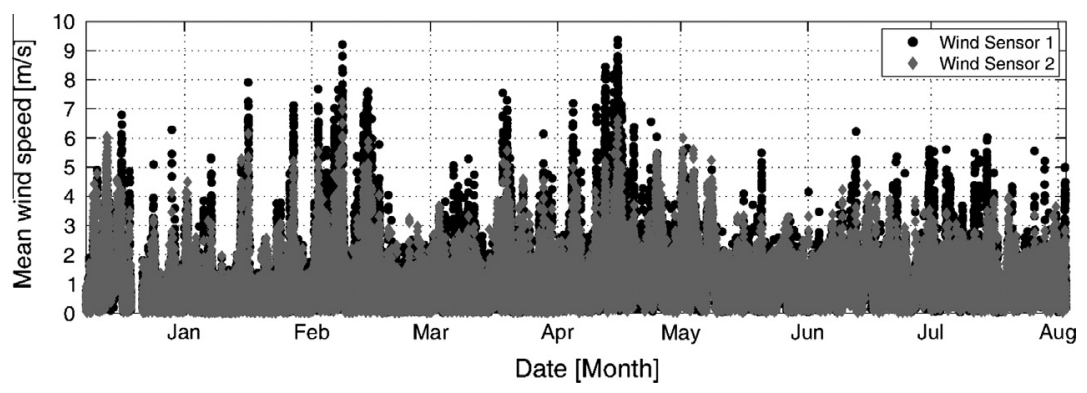

Fig. 4. Time-history of 10-min mean wind speed measured by the two sonic anemometers over the period of 8 months.

will be considered and all measurements with 10-min mean wind speed below $4 \mathrm{~m} / \mathrm{s}$ will be discarded.

Wind direction distribution is shown in the wind rose histograms of Fig. 5. These illustrations show, by means of a polar histogram, the dominant directions categorised by wind speed magnitude.

Fig. 5(a), relative to sensor WS1, shows a strong dominance by winds from the north-west-north-east sector, with the greatest frequencies from north and north-west. Within this sector, an important percentage of observations lies in the higher wind speeds, between 6 and $10 \mathrm{~m} / \mathrm{s}$. Relevant wind speeds are also observed from the east and south directions, with much smaller frequencies and lower wind speeds. The distribution observed by sensor WS2 Fig. 5(b) is somewhat different. The sectors with relevant wind speeds are much narrower, with the highest frequency of observations from south, although with relatively low wind speeds. For this sensor the highest wind speeds were observed between north-east and north, while never surpassing $8 \mathrm{~m} / \mathrm{s}$.

Comparing the direction distributions obtained for both sensors, two major differences can be stressed: while the northwest-north winds are more dominant for WS1, the sensor WS2 displays a greater amount of observations from the south direction; and the wind speeds observed from WS1 are generally greater than from WS2, especially from the north-west-north sector.

Besides the horizontal direction, Fig. 6 depicts the distribution of the incidence angle and respective wind speed with the orientation. While negative and positive values of incidence account for descending and ascending angles respectively, the size and shade of each point evidence the measured mean speed.

In both Fig. 6(a) and (b), corresponding to sensors WS1 and WS2 respectively, the measured incidence angles can be divided into two almost distinct clusters of data points: one mostly with values below the $0^{\circ}$ line and other almost exclusively with positive incidence values.

For sensor WS1 (Fig. 6(a)) the negative incidence angles are centred around the east and south directions while the positive values span from north-west to north-east. Negative incidence values range between approximately $-7^{\circ}$ and $0^{\circ}$ with wind speeds relatively low. The spread of the positive incidence points is bigger, ranging from approximately $0^{\circ}$ to $10^{\circ}$. This last cluster shows much higher mean wind speeds.

Negative incidence angles for sensor WS2 (Fig. 6(b)) show a very narrow spread around the south direction, with values varying from $-5^{\circ}$ to $0^{\circ}$. Positive values are distributed between north-west and north-east and show a very wide incidence distribution. While the minimum values approximate $0^{\circ}$, the maximum reaches nearly $25^{\circ}$ for the north direction. Wind speeds observed are low in each case, with relatively higher values for positive incidence angles.

The presented results are in agreement with the expected wind behaviour for the structure's implantation in the terrain and the sensors position on the structure. As previously seen, the stadium is positioned approximately along the north-east-north-west axis (see Fig. 1(a)) and the anemometers located on the west roof slab (see Fig. 3). In both cases, the winds measured from south come from the top of the west slab, accordingly they must have descending incidence angle, while the wind from the northwest-north-east sector flows from the stadium open side, reaching the anemometers with ascending incidence. The most unusual results observed were the high incidence angles measured by the sonic anemometer WS2 (Fig. 6(b)). This phenomenon can be explained by the north and north-west winds that reach this
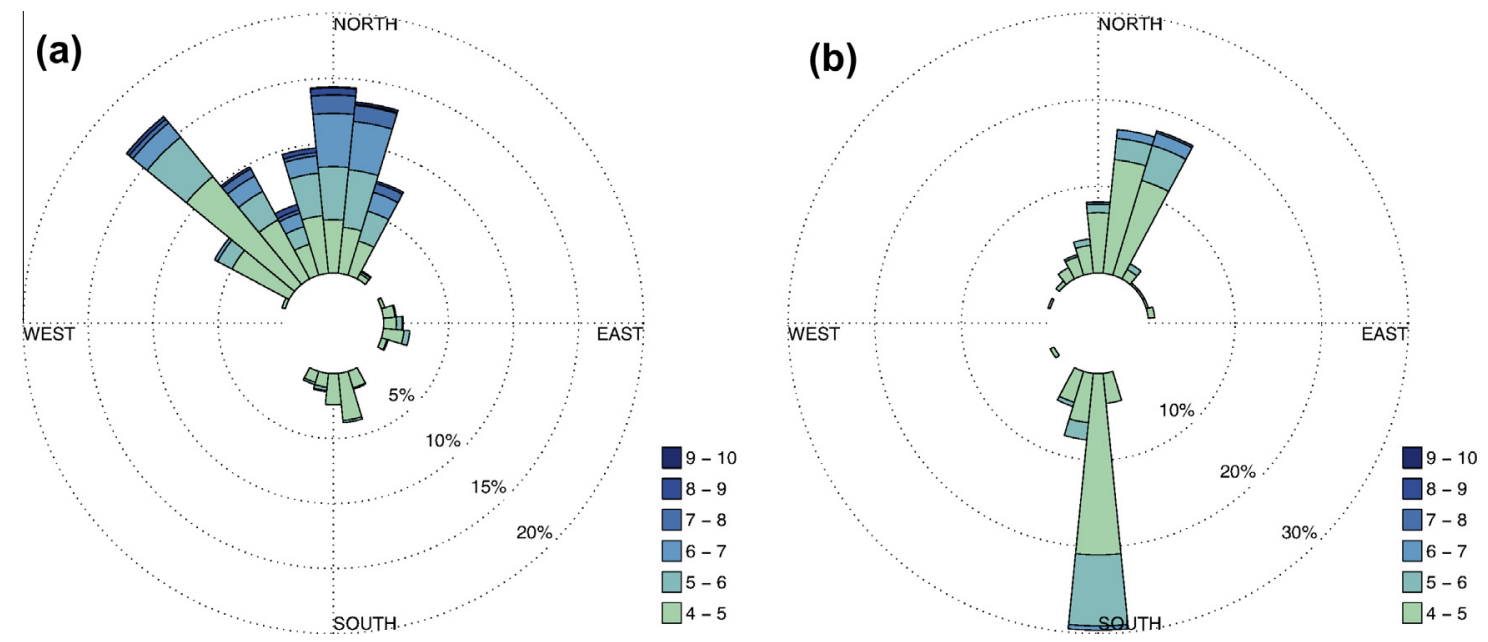

Fig. 5. Wind rose histograms of 10-min mean speed and corresponding direction for sonic anemometers: (a) WS1 and (b) WS2. 

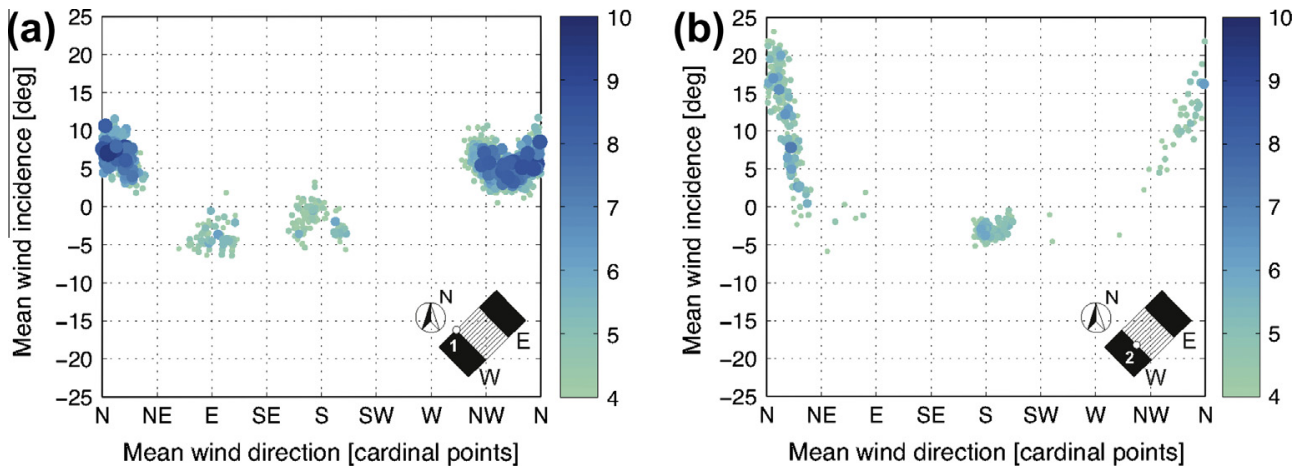

Fig. 6. Distribution of 10-min mean wind speed with direction and incidence angles measured by sonic anemometers: (a) WS1 and (b) WS2.

sensor (located in the middle of the west slab as seen in Fig. 3) being strongly influenced by the stadium structure.

\subsection{Turbulence intensity}

Turbulence intensity describes the characteristics of the fluctuating wind speed. The longitudinal, $u$, lateral, $v$, and vertical, $w$, turbulence intensities can be determined by the following equations:

$I_{u}=\frac{\sigma_{u}}{\bar{U}}, \quad I_{v}=\frac{\sigma_{v}}{\bar{U}}, \quad I_{w}=\frac{\sigma_{w}}{\bar{U}}$

where $\sigma_{u}, \sigma_{v}$ and $\sigma_{w}$ are the standard deviation or the RMS of each fluctuating velocity component and $U$ is the wind mean speed for the same time period. In this study, the same 10-min period used before was adopted for the calculation of these parameters.

Fig. 7 shows the variations of the longitudinal, lateral and vertical turbulence intensities as a function of the mean wind speed, independent of direction and incidence angles, for sensors WS1 and WS2. A general trend for $I_{u}>I_{v}>I_{w}$ is noticed across both sensors data.

Fig. 7(a-c), representing the three components of turbulence intensity measured by sonic anemometer WS1, reveals a standard pattern of variation of the turbulence intensities with wind speed, where turbulence intensity shows a clear trend to decrease and narrow its spread for higher mean wind speeds. The mean values found for the longitudinal, lateral and vertical turbulence intensities were $0.296,0.266$ and 0.165 , respectively, which result in a relative ratio of $\sigma_{u}: \sigma_{v}: \sigma_{w}=1: 0.900: 0.556$. On the other hand, the turbulence intensities variation with wind speed measured by sonic anemometer WS2, represented in Fig. 7(d-f), shows a very scattered distribution. However, the same downward trend can be identified for the three turbulence intensities components $\left(\sigma_{u}, \sigma_{v}\right.$ and $\sigma_{w}$ ), although less pronounced. The ratios between the averaged values of the turbulence intensity in the three directions for this sensor are $\sigma_{u}: \sigma_{v}: \sigma_{w}=1: 0.789: 0.543$. The $\sigma_{w} / \sigma_{u}$ values are very close to the ratio proposed by Solari and Piccardo [36] of
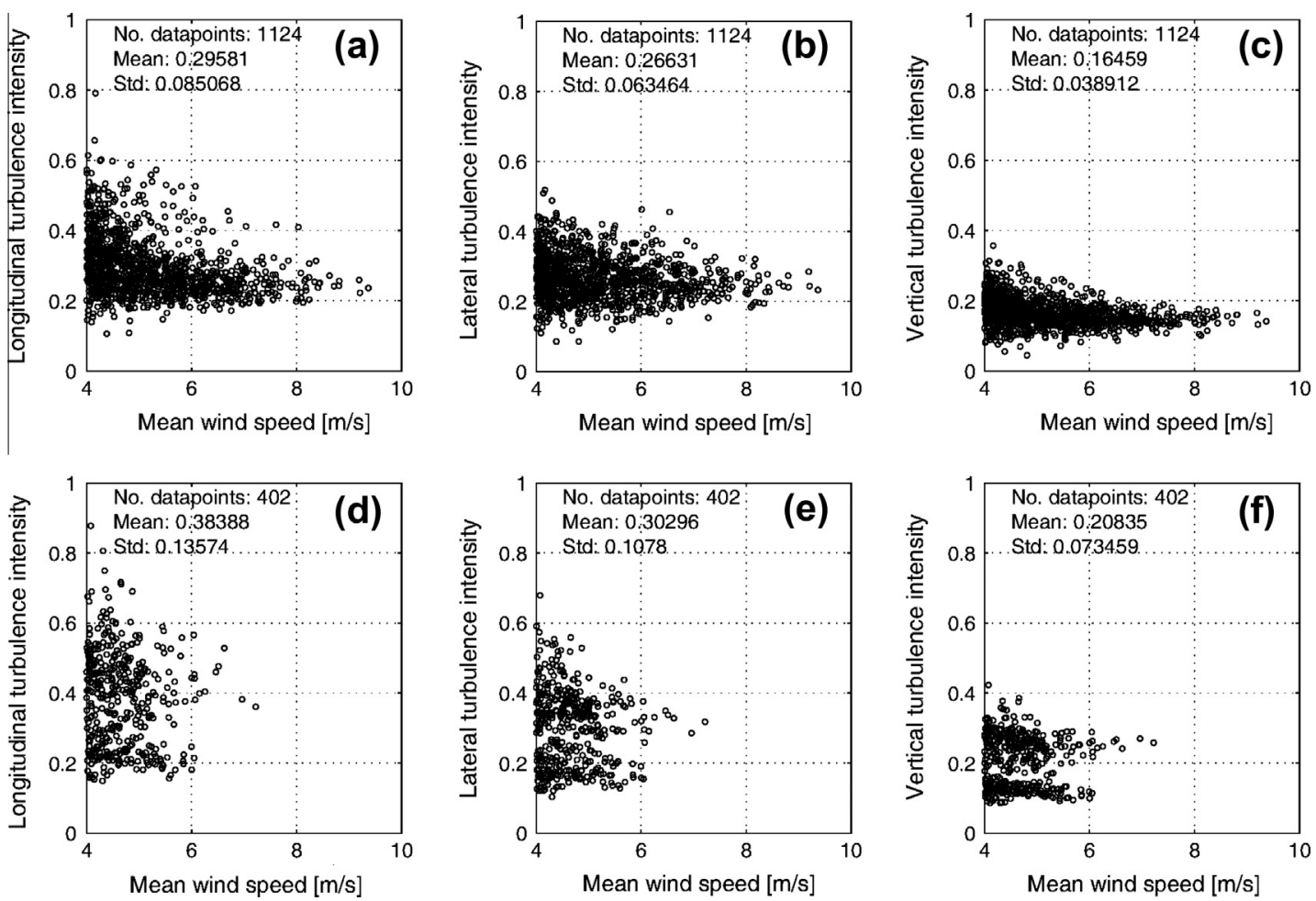

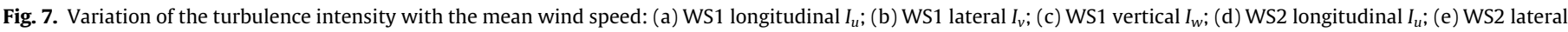
$I_{v} ;$ and (f) WS2 vertical $I_{w}$ 
$E\left[\sigma_{w} / \sigma_{u}\right]=0.5$. The ratio $\sigma_{w} / \sigma_{u}$ obtained for WS1 differs from this author proposal of $E\left[\sigma_{w} / \sigma_{u}\right]=0.75$, but is well approximated by WS2.

The turbulence intensity is simply related to the surface roughness [8], and therefore to the wind incoming direction. In Fig. 7 turbulence intensities from all incoming directions are represented, leading to a wide spread distribution, especially in the case of WS2. Shown in Fig. 8 are longitudinal, lateral and vertical turbulence intensities as a function of the 10-min mean wind direction, and the respective mean wind speed. From these, characteristic turbulence intensities can be identified by direction and a consistent evolution through direction is perceived.

Fig. 9 shows the variation of the averaged longitudinal, lateral and vertical turbulence intensities as a function of the 10 -min mean wind direction, categorised in sixteen $22.5^{\circ}$ directional sectors. It is noted from Fig. 9(a), corresponding to sensor WS1, that the three component turbulent intensities are rather homogeneous across all directions, with the exception of the two upward trends: one between SE and SSW; and other between N and WNW. On the other hand, measurements from wind sensor WS2 (see Fig. 9(b)) reveal two rather distinct clusters: one, centred on the south direction, with an upward trend from SSE to SSW and a very narrow spread in direction; and another, centred on the north direction, with turbulence intensities generally greater than the first.

The variation of the averaged turbulence intensity ratios $\sigma_{v} / \sigma_{u}$ and $\sigma_{w} / \sigma_{u}$ as a function of mean direction, categorised in 16 directional sectors, is translated by Fig. 10. Overlaid is the number of data points measured for each direction sector, expressed by a histogram. Both WS1 and WS2 $\sigma_{w} / \sigma_{u}$ ratios show a rather uniform variation across all analysed sectors, with values close to the Solari and Piccardo [40] ratio estimate of 0.5. Meanwhile, the $\sigma_{v} / \sigma_{u}$ ratio shows a fairly distinct variation between the two sonic anemometers measurements and, in most cases, very different values from the proposed by Solari and Piccardo [40] of 0.75 . The highest ratios found for WS1 surpass the unit and refer to the two sectors around north. On the other hand, the two sectors about the south direction show ratios close to 0.75 . Two peaks can be identified: the higher, around north, and a lower, around ESE. Meanwhile, for WS2 the maximum average ratio $\sigma_{v} / \sigma_{u}$ was 1.09 for the SW-SWW sector, although just two data points were identified for this direction. Sectors about north and south show values fairly close to 0.75 , while other sectors exhibit slightly higher values. $\sigma_{v} / \sigma_{u}$ ratios greater than 1 point to a lateral turbulence greater than the longitudinal turbulence, phenomenon rather unusual, but possible in some circumstances [41].

\subsection{Power spectrum of wind speed}

Power spectrum density functions display the energy distribution of the wind speed fluctuating components. Different representations of these functions have been proposed in the literature. The proposal of the von Kármán spectrum [1] remains as one of the most widely accepted [42]. This model is particularly suitable for conditions where the low-frequency region is of greater importance, which is the case of Braga Stadium suspension roof. The von Kármán reduced auto power spectrum for the along-wind component is defined as:

$$
\frac{n S_{u}(n)}{\sigma_{u}^{2}}=\frac{4 \cdot \frac{n L_{u}}{\bar{U}}}{\left[1+70.8\left(\frac{n L_{u}}{\bar{U}}\right)^{2}\right]^{5 / 6}}
$$

where $n$ is the frequency, $S_{u}(n)$ is the along-wind auto power spectrum, $\sigma_{u}$ is the standard deviation of the longitudinal turbulence $u$, $U$ is the mean wind speed and $L_{u}$ is the estimated turbulence integral length scale of the longitudinal wind speed component. For the cross-wind and vertical components, the von Kármán model has the following form:

$$
\frac{n S_{\epsilon}(n)}{\sigma_{\epsilon}^{2}}=\frac{4 \cdot \frac{n L_{\epsilon}}{\bar{U}}\left[1+755.2\left(\frac{n L_{\epsilon}}{\bar{U}}\right)^{2}\right]}{\left[1+283.2\left(\frac{n L_{\epsilon}}{\bar{U}}\right)^{2}\right]^{11 / 6}}(\epsilon=v, w)
$$

where $S_{v}(n)$ and $S_{w}(n)$ are the cross-wind and vertical auto power spectra, $\sigma_{v}$ and $\sigma_{w}$ are the standard deviation of the lateral and
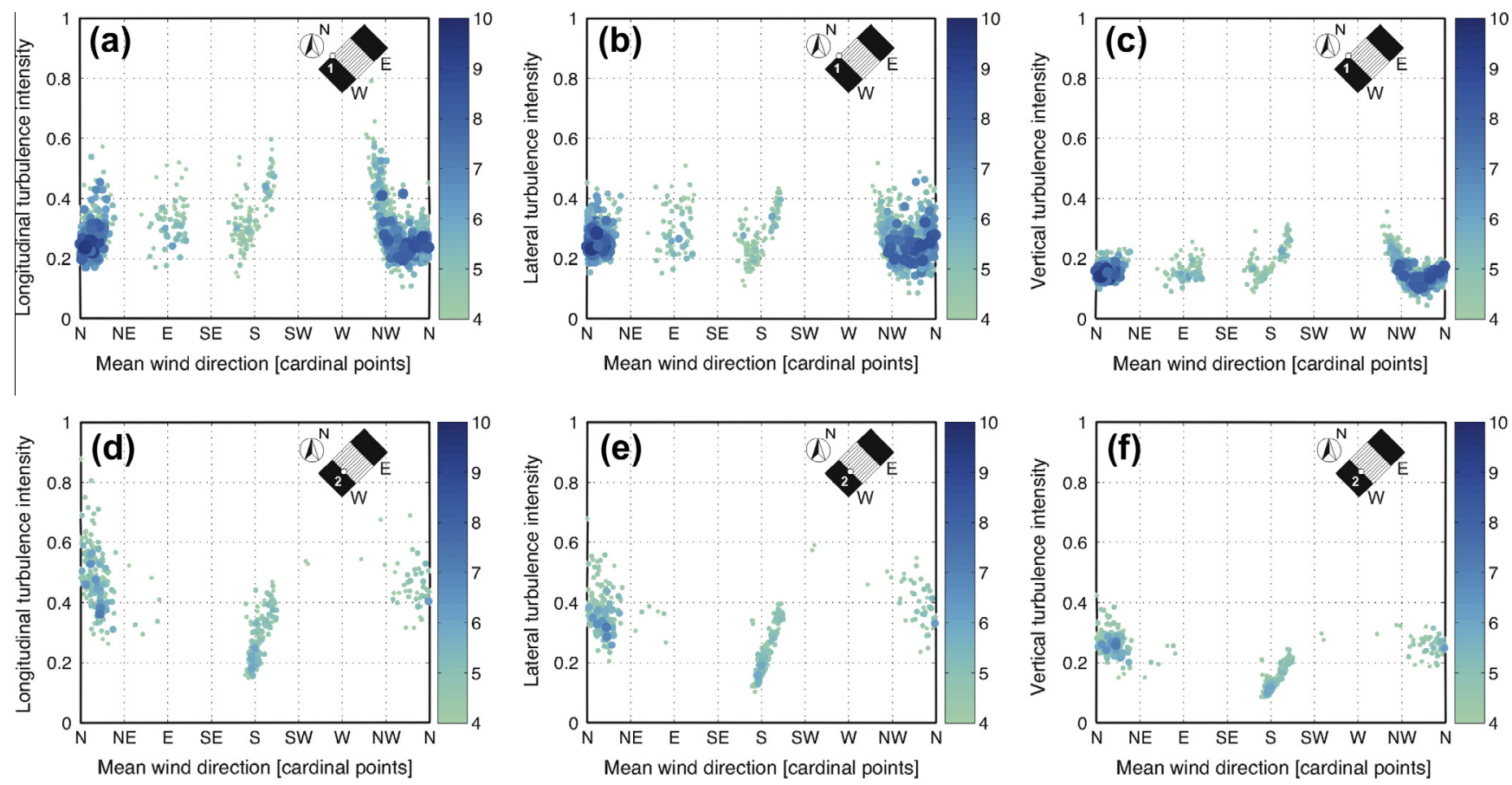

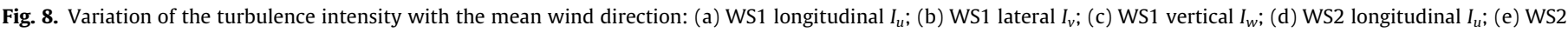
lateral $I_{v}$; and (f) WS2 vertical $I_{W}$ 

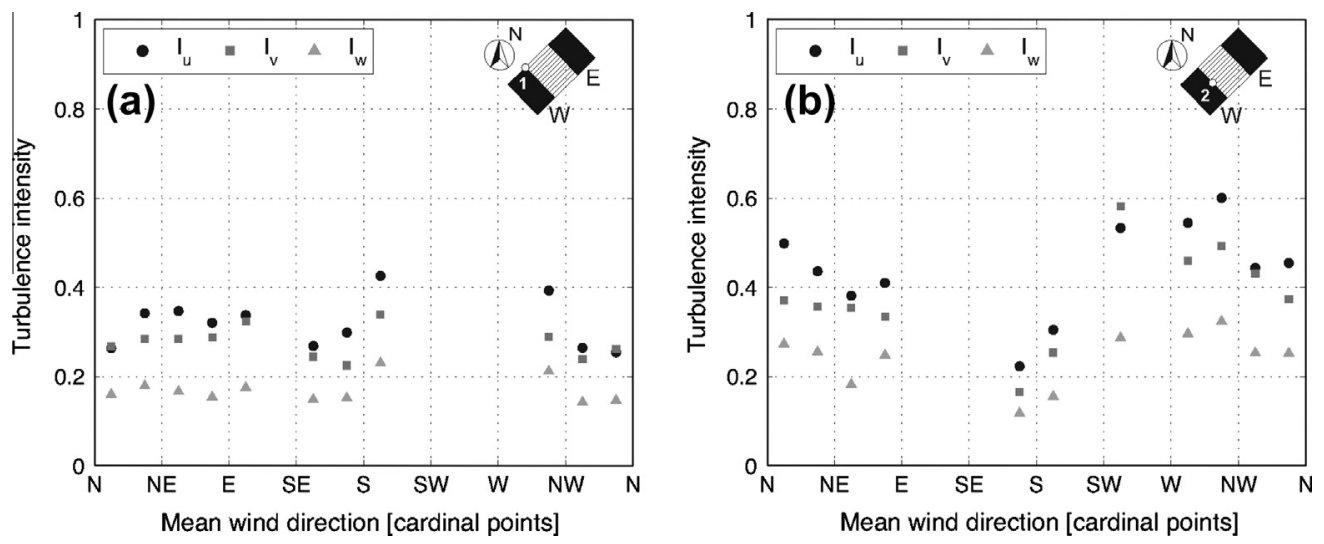

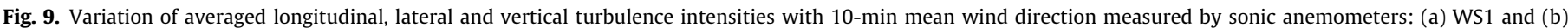
WS2.

vertical turbulences and $L_{v}$ and $L_{w}$ are the integral length scales of the cross-wind and vertical turbulence, respectively.

Two samples of wind data with very distinct characteristics were selected for spectral analysis, both measured by sonic anemometer WS1. The criterion for this selection was the extraction of 2-h records with relatively high mean wind speed, but with opposite mean direction and incidence angles. Also, the wind sample should exhibit stationary characteristics, i.e., the mean wind speed from each segment should not differ more than $25 \%$ from the wind speed mean of the full time series and, additionally, the corresponding direction angle must not vary by more than $15^{\circ}$ [7].

The first sample chosen, with a north direction $\left(15.9^{\circ}\right)$ and an upward incidence $\left(6.85^{\circ}\right)$ was collected on 8 February 2012 between 11:50 and 13:50, and shows a mean wind speed of $7.73 \mathrm{~m} / \mathrm{s}$. The second sample, measured on the 25 April 2012 between $13: 30$ and $15: 30$, is characterised by a south direction $\left(193^{\circ}\right)$, a downward incidence $\left(-2.94^{\circ}\right)$ and a mean wind speed of $4.69 \mathrm{~m} / \mathrm{s}$.

In order to obtain the power spectrum density function (PSD) for each turbulent component, the time series are divided into data segments with 8192 points and a 50\% overlap over the previous and following windows. After applying a Hanning window to all time series segments, a fast Fourier transform is used to compute individual PSDs. Global auto power spectra function are obtained by averaging all individual PSDs previously obtained.

The reduced auto power spectra computed for both wind samples for each turbulent component are depicted in Fig. 11.

\subsection{Turbulence integral length scales}

The turbulence length scales define the average size of the turbulent eddies of the flow. Several criteria can be used to estimate these parameters. In the approach used in this study the turbulence integral length scales were estimated by fitting the parameters of Eqs. (2) and (3) to the observed velocity spectra.

The von Kármán spectra fitted to the power spectra density functions are represented in Fig. 11, together with the resulting integral length scale. The von Kármán spectrum appears to fit relatively well the spectra obtained from the field measurements, especially in the case of southern winds in the low frequency range.

The values of the turbulence integral length scale obtained for the along-wind, cross-wind and vertical wind directions are, respectively, $110.4 \mathrm{~m}, 41.85 \mathrm{~m}$ and $8.896 \mathrm{~m}$ for northern winds and $40.45 \mathrm{~m}, 11.99 \mathrm{~m}$ and $3.817 \mathrm{~m}$ for southern winds. A prominent distinction is found between the parameters obtained for the two opposite prevailing directions. Turbulence integral length scales from northern winds present values 2-3.5 times greater than those measured from southern winds.

Based on many field measurements, Solari and Piccardo [40] proposed that the turbulence integral length scales can be estimated by:

$$
L_{\epsilon}(z)=300 \lambda_{\epsilon}(z / 200)^{v} ; \quad v=0.67+0.05 \ln \left(z_{0}\right) \quad(\epsilon=u, v, w)
$$

where $L_{\varepsilon}$ is the integral length scale for the given direction $(u, v$ or $w), z$ is the height above the ground $(z \leqslant 200 \mathrm{~m})$, and $z_{0}$ is the
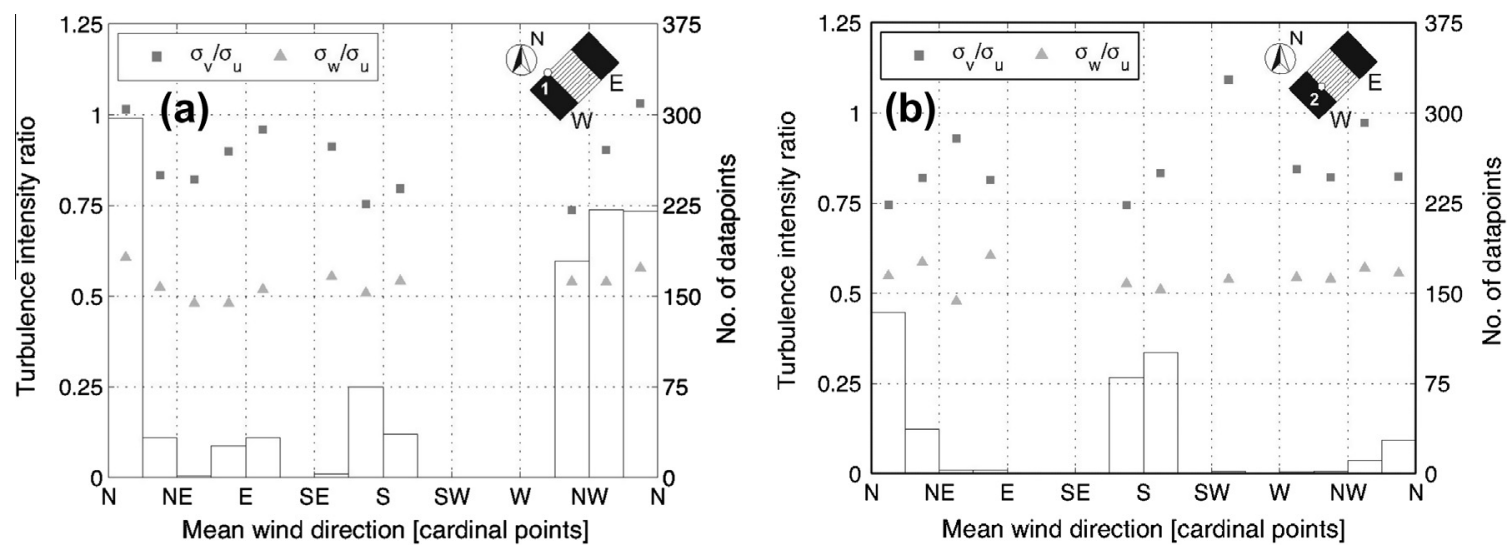

Fig. 10. Variation of averaged turbulence intensities ratios $\sigma_{v} / \sigma_{u}$ and $\sigma_{w} / \sigma_{u}$ as a function of 10-min mean wind direction: (a) WS1 and (b) WS2. 

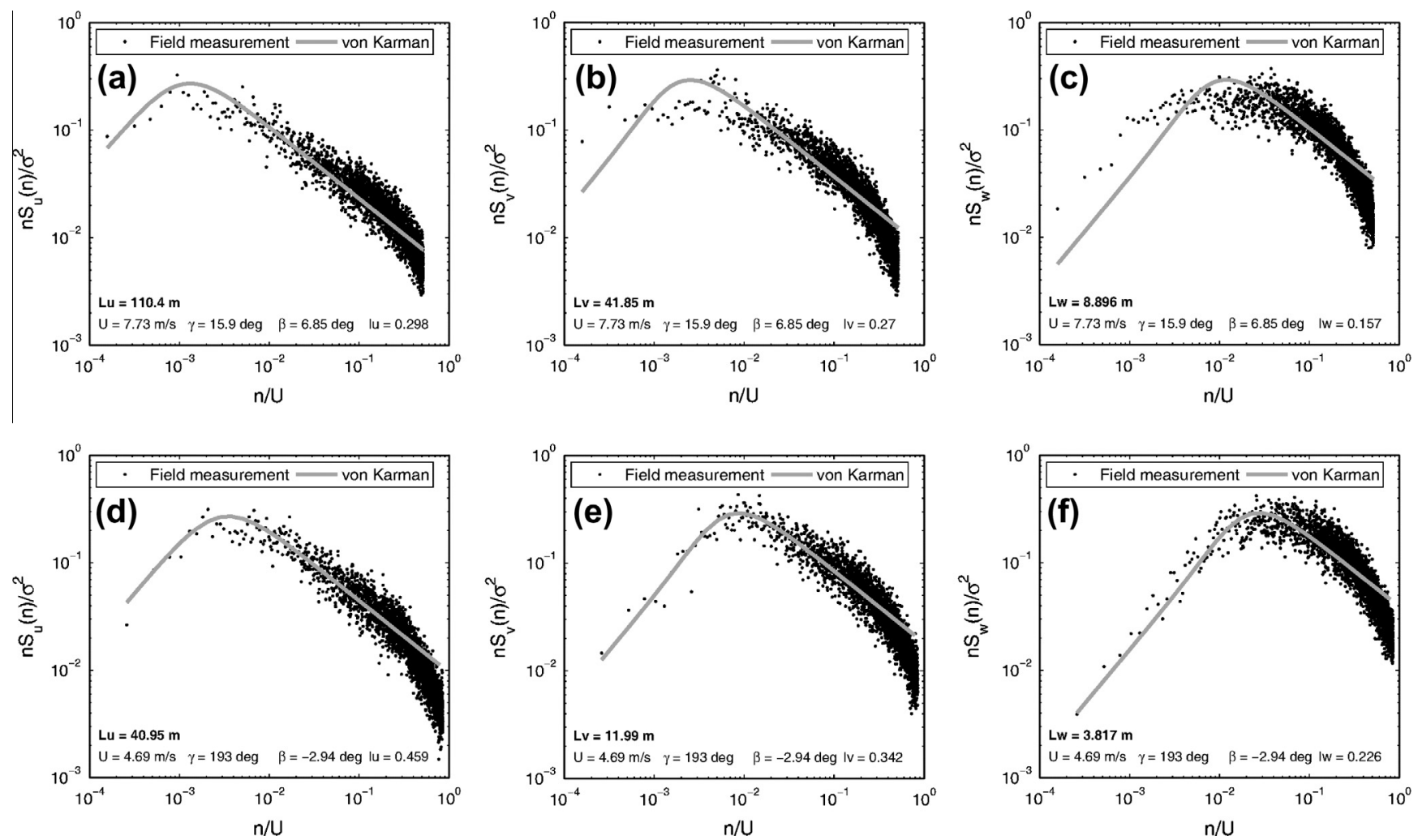

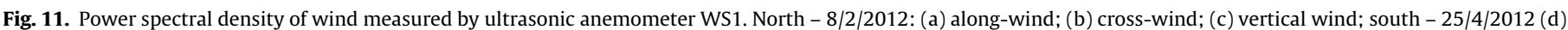
along-wind; (e) cross-wind; (f) vertical wind.

roughness length, all in meters. $\lambda_{\varepsilon}$ is a random variable that assumes the value of $1,0.25$ and 0.10 for the three orthogonal directions $u, v$ and $w$.

Taking into account that the ultrasonic anemometer WS1 is placed at approximately $35 \mathrm{~m}$ height and assuming a terrain roughness of $z_{0}=0.15 \mathrm{~m}$, value in between categories I and II from Eurocode 1 - Part 1-4 [43], turbulence integral length scales were assessed based on Eq. (4). The values obtained were $110.1 \mathrm{~m}$, $27.52 \mathrm{~m}$ and $11.01 \mathrm{~m}$ for the along-wind, cross-wind and vertical wind direction, respectively. While these estimates approximate rather well the along-wind and vertical wind turbulence integral length scales measured for the northern winds, they fail to assess the southern winds values. Considering that the wind from the south direction flows through the west slab and from the terrain behind it at the same level, it is reasonable to consider different height from the ground $z$ and terrain roughness $z_{0}$ properties (see Figs. 1 and 2). Assuming the ultrasonic anemometer elevation above the west slab at the height $z=3 \mathrm{~m}$ and a upstream roughness characteristic of smoother terrains $z_{0}=0.02 \mathrm{~m}$ the following length scales are obtained from Eq. (4): $L_{u}=40.91 \mathrm{~m}, L_{v}=10.23 \mathrm{~m}$ and $L_{w}=4.09 \mathrm{~m}$. Comparing these with the measured parameters from the south wind sample, a rather good match is noticed for all three directions.

The ratios between the three values of turbulence integral length scale measured in the along-wind, cross-wind and vertical wind direction are $L_{u}: L_{v}: L_{w}=1: 0.38: 0.08$ for northern winds and $L_{u}: L_{v}: L_{w}=1: 0.29: 0.09$ for winds upcoming from south. For both cases the ratio $L_{w} / L_{u}$ obtained matches the value predicted by Solari and Piccardo [40] of 0.1. On the other hand, both ratios $L_{v} / L_{u}$ measured disagree with these authors' estimate of 0.25 . Nevertheless, both obtained ratios $L_{v} / L_{u}$ and $L_{w} / L_{u}$ are consistent with values obtained by several other authors and are in accordance with the range presented by Solari and Piccardo [40].

\section{Modal parameters}

The automatic identification of the modal parameters (natural frequencies, mode shapes and damping ratios) is performed based on the ambient vibration response continuously measured by the dynamic monitoring system. For this purpose, developed algorithms process 60 -min acceleration files using the Covariance driven Stochastic Subspace Identification method (SSI-COV) complemented with a methodology based on the hierarchical clustering algorithm to automatically interpret stabilisation diagrams [44].

Fig. 12 shows the evolution of the 12 identified natural frequencies of the roof structure in the range $0.1-1.1 \mathrm{~Hz}$ since the installation of the wind measurements system, in December 2011, until the first days of August 2012. A sample of 9 days evolution of natural frequencies from modes 3, 4 and 5 is presented in Fig. 13(b), corresponding to the mean wind speed and temperature variations represented in Fig. 13(a). Here, a daily variation effect of environmental (temperature and wind) and operational (activities in the vicinity of the stadium) factors, can be observed for each mode. It is interesting to note that temperature and wind can affect differently the different modes: evolution of the natural frequencies of 3rd and 4th modes is contrary to the 5th mode. Representation of the corresponding modal configurations is shown in Fig. 14.

Fig. 13(c) represents the variation of the damping ratio correspondent to modes 3, 4 and 5 during the same period of 9 days shown. Contrary to the well-defined evolution of natural frequencies, modal damping ratios exhibit significant scatter. This is not only due to the higher uncertainty associated with the estimation of these parameters, but also to the significant dependence on other variables, like wind and vibration amplitude. Nevertheless, a faint daily pattern can be observed, outcome of temperature and wind speed variation. Fig. 15 characterises, resorting to 


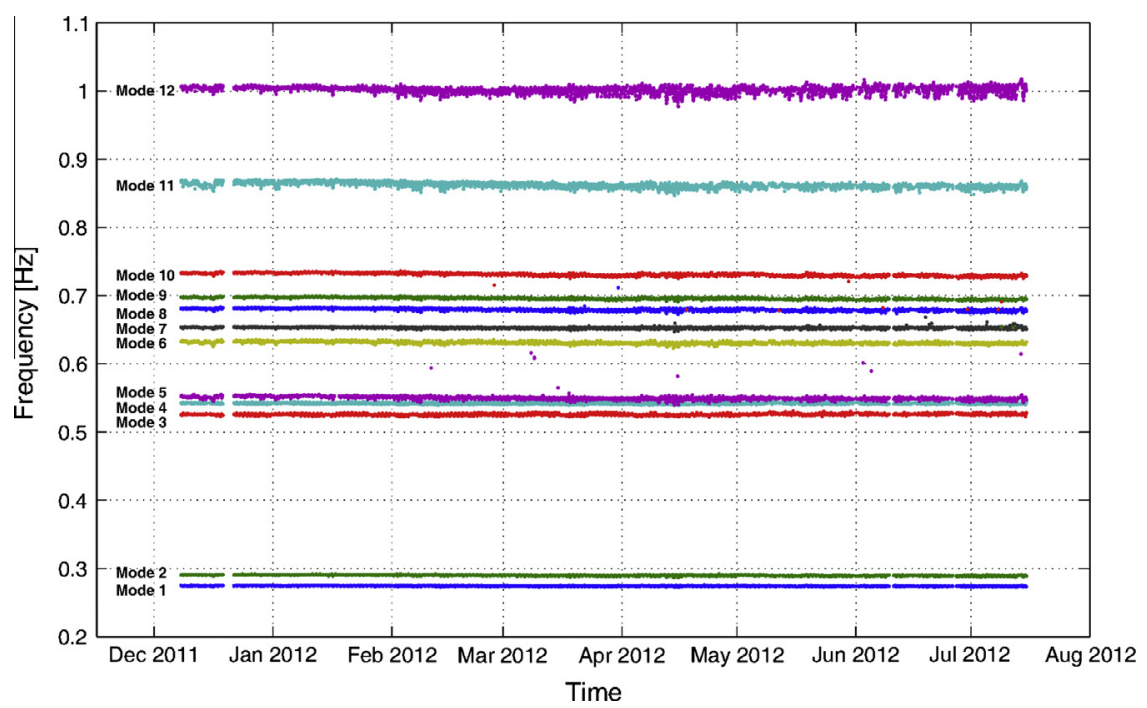

Fig. 12. Time evolution of 12 first natural frequencies from December 2011 to August 2012.
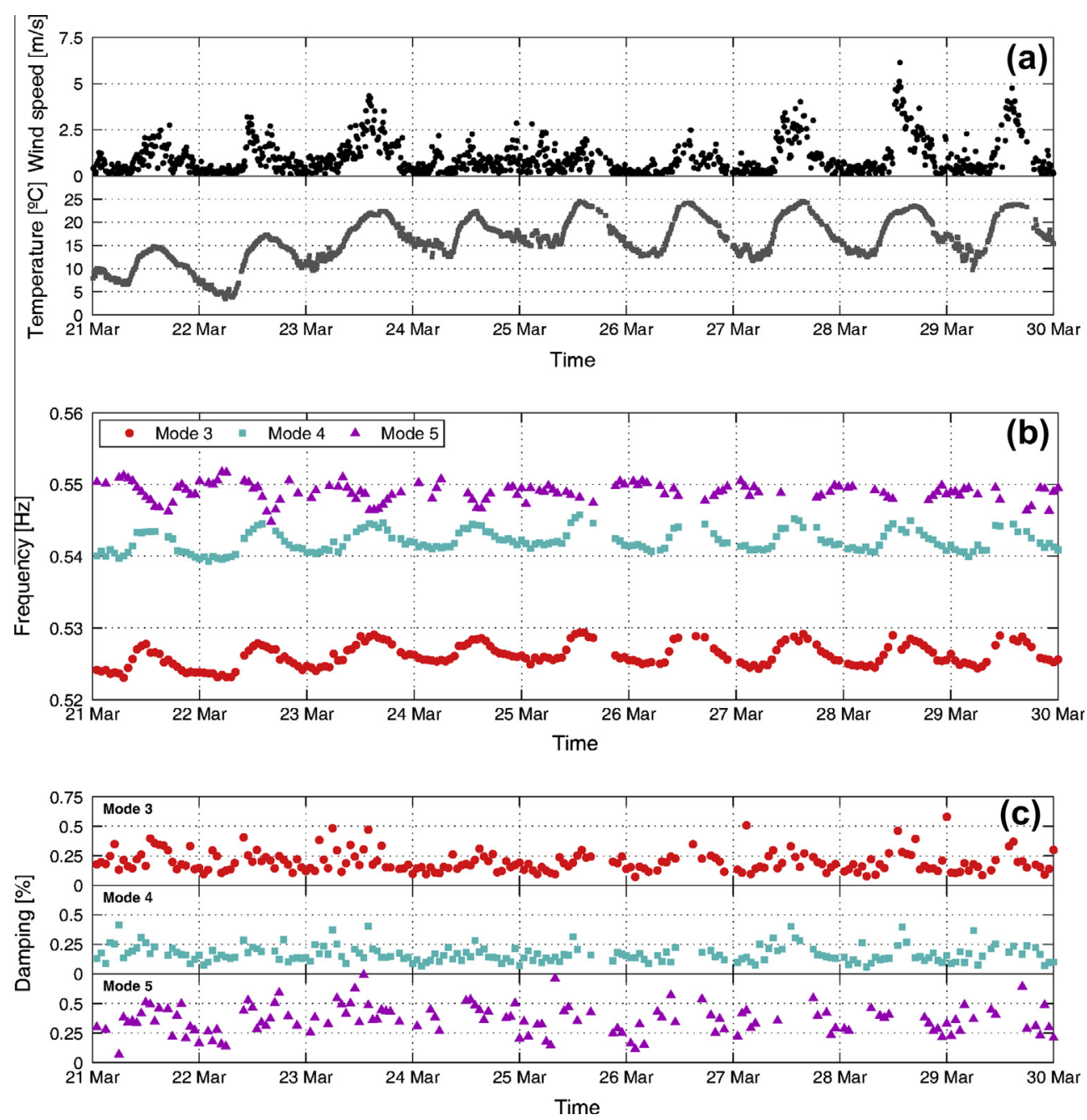

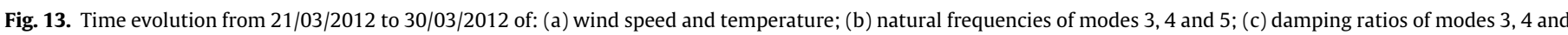
5 during the same period.

histograms, the dominant values and variability of the identified modal damping ratios during the period of 8 months.

Table 1 summarises the mean and standard deviation values obtained for the analysis of the natural frequencies and damping ratios identified during the above mentioned period. The higher variability in the estimation of damping ratios, in contrast with the natural frequencies, is evident in this table. It is also worth noting the very low values found for the damping ratios, also patent in 


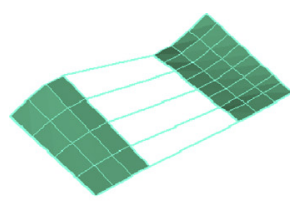

$f_{1}=0.275 \mathrm{~Hz}$

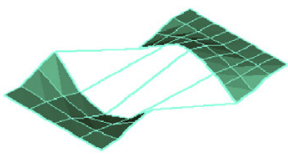

$f_{5}=0.550 \mathrm{~Hz}$

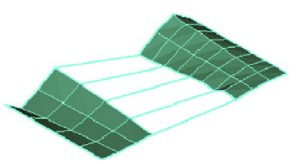

$f_{9}=0.696 \mathrm{~Hz}$

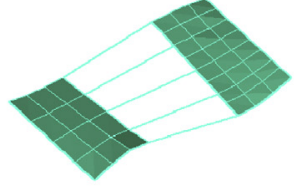

$f_{2}=0.290 \mathrm{~Hz}$

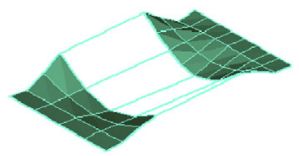

$f_{6}=0.631 \mathrm{~Hz}$

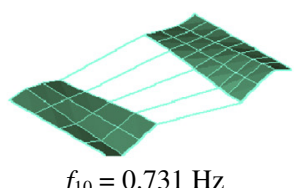

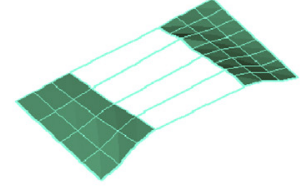

$f_{3}=0.526 \mathrm{~Hz}$
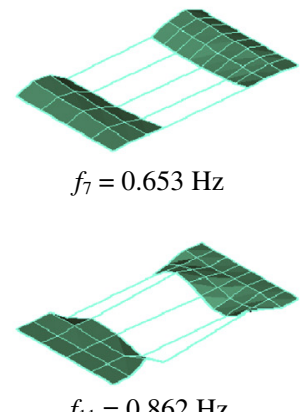

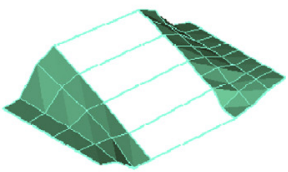

$f_{4}=0.552 \mathrm{~Hz}$
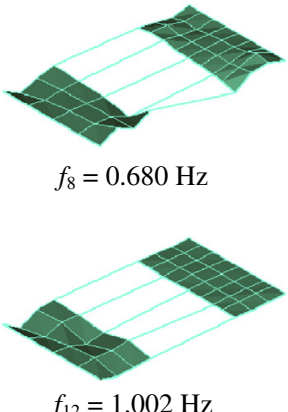

Fig. 14. Identified modal configurations associated with the first twelve modes.

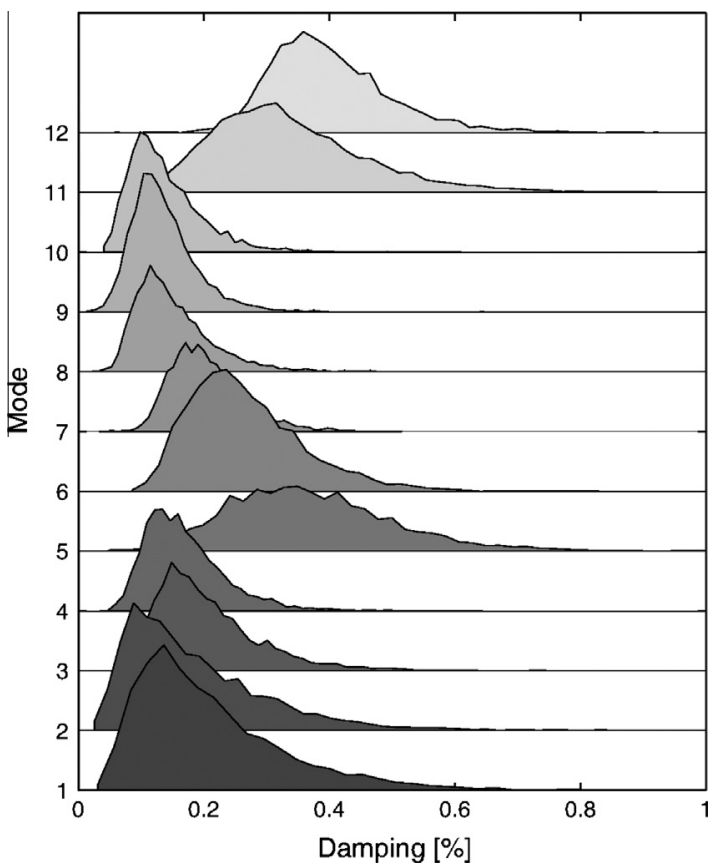

Fig. 15. Dispersion of the identified modal damping ratios for the 12 first modes.

Table 1

Mean and standard deviation values of the natural frequencies and damping ratios identified in the period between December 2011 and August 2012.

\begin{tabular}{|c|c|c|c|c|}
\hline \multirow[t]{2}{*}{ Mode } & \multicolumn{2}{|c|}{ Frequency (Hz) } & \multicolumn{2}{|c|}{ Damping (\%) } \\
\hline & Mean & Std. & Mean & Std. \\
\hline 1 & 0.275 & 0.001 & 0.21 & 0.12 \\
\hline 2 & 0.290 & 0.001 & 0.19 & 0.11 \\
\hline 3 & 0.526 & 0.002 & 0.21 & 0.08 \\
\hline 4 & 0.542 & 0.001 & 0.17 & 0.07 \\
\hline 5 & 0.555 & 0.004 & 0.38 & 0.13 \\
\hline 6 & 0.631 & 0.002 & 0.27 & 0.09 \\
\hline 7 & 0.653 & 0.001 & 0.21 & 0.06 \\
\hline 8 & 0.680 & 0.004 & 0.15 & 0.06 \\
\hline 9 & 0.696 & 0.002 & 0.14 & 0.05 \\
\hline 10 & 0.731 & 0.003 & 0.14 & 0.06 \\
\hline 11 & 0.862 & 0.004 & 0.33 & 0.12 \\
\hline 12 & 1.002 & 0.005 & 0.40 & 0.10 \\
\hline
\end{tabular}

Fig. 15, that are coherent with the results from the ambient vibration and free vibration tests previously conducted [33].

\section{Influence of wind and temperature on modal parameters}

\subsection{Wind induced response}

In this section, the influence of wind speed on structural response is described by the relationship between the 10 -min root-mean-square (RMS) acceleration response and the mean wind speed and direction for the same period of time. The vertical acceleration response measured by the six accelerometers of the monitoring system was analysed for periods of time in which the 10-min mean wind speed measured by WS1 (Fig. 3) were greater than $4 \mathrm{~m} / \mathrm{s}$. Furthermore, the analysis took into account the 10 -min mean wind direction, dividing acceleration responses according to sixteen $22.5^{\circ}$ directional sectors.

Fig. 16 shows the relationship between the mean wind speed measured by WS1 and the vertical RMS accelerations measured by each accelerometer according to the three dominant wind directions. From the performed analysis only the three directional sectors between $315^{\circ}(\mathrm{NW})$ and $22.5^{\circ}$ (NNE) showed a reasonable amount of observations.

The analysis of Fig. 16 clearly shows the similarities in acceleration magnitude between accelerometers in the same suspension roof longitudinal direction (A1-A4, A2-A5 and A3-A6) (see Fig. 3). It is also noticeable that sensors placed near the slab inner edge (A1, A2 and A3) show higher RMS accelerations than the correspondent sensors placed along the middle of the slab (A4, A5 and A6).

The acceleration levels observed for each of the six accelerometers, and the relation between them, reflect the modal shapes of the first vibration modes (see Fig. 14). Table 2 lists the maximum RMS and the maximum acceleration obtained for each direction in each accelerometer. The accelerometers placed on the northwest border of the slab (A3 and A6) show the highest magnitudes of acceleration, with nearly $0.03 \mathrm{~m} / \mathrm{s}^{2}$ RMS and $0.13 \mathrm{~m} / \mathrm{s}^{2}$ maximum for the higher wind speeds. On the other hand, the accelerometers A2 and A5, set on the middle of the slab, measure the lowest acceleration values.

From Fig. 16, one can also observe a general trend of increase of the vertical RMS acceleration response with the mean wind speed. This trend appears clearer for individual directions. The observed response is characteristic of a turbulence buffeting model, where the vibration mechanism is controlled by turbulent random pressure fluctuations 


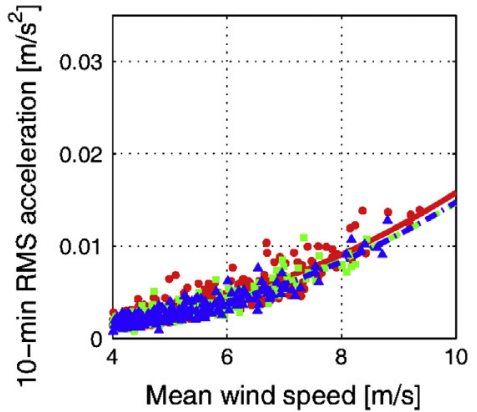

(a) A4

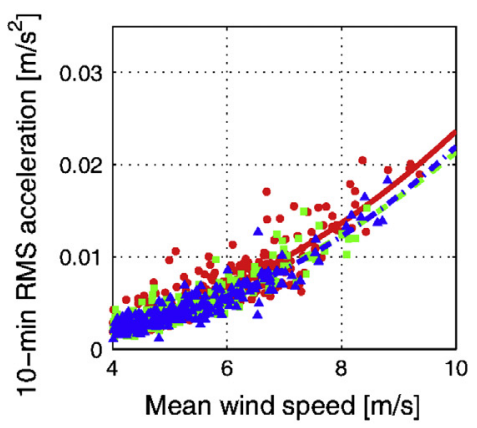

(d) A1

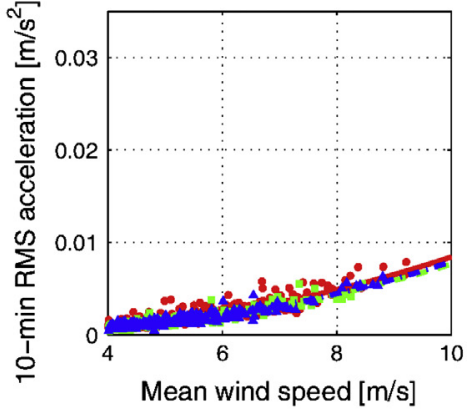

(b) A5

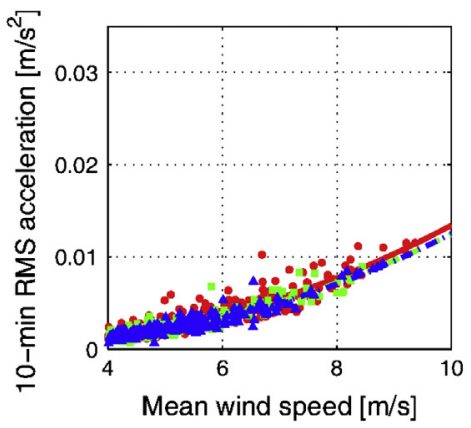

(e) A2

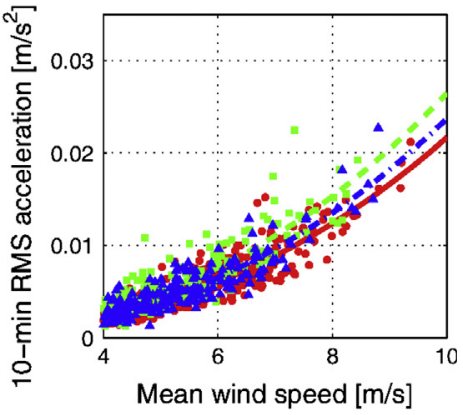

(c) A6

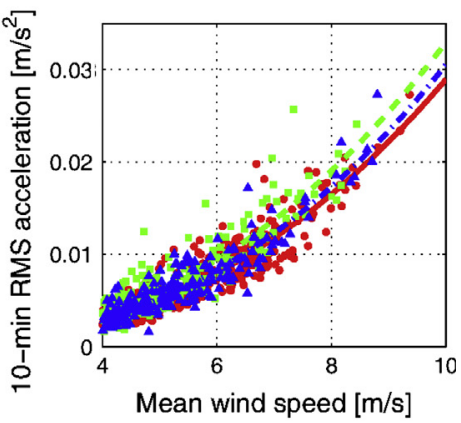

(f) A3

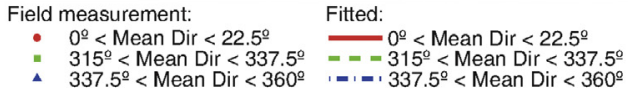

Fig. 16. Relationship between mean wind speed from 3 dominant wind directions and 10-min RMS acceleration (see Fig. 3).

Table 2

Maximum acceleration and regression curves parameters of the acceleration responses by wind direction sector.

\begin{tabular}{|c|c|c|c|c|c|}
\hline Accel. & Direction $\left({ }^{\circ}\right)$ & Max. RMS accel. $\left(\times 10^{-2} \mathrm{~m} / \mathrm{s}^{2}\right)$ & Max. accel. $\left(\times 10^{-2} \mathrm{~m} / \mathrm{s}^{2}\right)$ & $c_{1}\left(\times 10^{-5}\right)$ & $c_{2}$ \\
\hline \multirow[t]{3}{*}{$\mathrm{A} 1$} & $0-22.5$ & 2.05 & 9.69 & 8.35 & 2.45 \\
\hline & $315-337.5$ & 1.53 & 8.87 & 7.41 & 2.46 \\
\hline & $337.5-360$ & 1.83 & 7.87 & 5.27 & 2.62 \\
\hline \multirow[t]{3}{*}{ A2 } & $0-22.5$ & 1.15 & 5.43 & 4.47 & 2.48 \\
\hline & $315-337.5$ & 0.90 & 4.80 & 4.15 & 2.48 \\
\hline & $337.5-360$ & 0.93 & 5.87 & 3.33 & 2.58 \\
\hline \multirow[t]{3}{*}{ A3 } & $0-22.5$ & 2.73 & 13.04 & 8.69 & 2.52 \\
\hline & $315-337.5$ & 2.57 & 9.86 & 11.6 & 2.45 \\
\hline & $337.5-360$ & 2.73 & 11.02 & 8.58 & 2.55 \\
\hline \multirow[t]{3}{*}{ A4 } & $0-22.5$ & 1.39 & 6.39 & 5.25 & 2.48 \\
\hline & $315-337.5$ & 1.09 & 5.23 & 4.73 & 2.49 \\
\hline & $337.5-360$ & 1.28 & 5.43 & 3.89 & 2.58 \\
\hline \multirow[t]{3}{*}{ A5 } & $0-22.5$ & 0.79 & 3.31 & 3.08 & 2.44 \\
\hline & $315-337.5$ & 0.55 & 2.77 & 2.49 & 2.49 \\
\hline & $337.5-360$ & 0.63 & 2.58 & 2.05 & 2.58 \\
\hline \multirow[t]{3}{*}{ A6 } & $0-22.5$ & 2.12 & 9.07 & 6.64 & 2.51 \\
\hline & $315-337.5$ & 2.25 & 8.63 & 9.37 & 2.45 \\
\hline & $337.5-360$ & 2.27 & 7.74 & 7.03 & 2.52 \\
\hline
\end{tabular}

[45]. This is further enhanced by the values of the acceleration peak factors at channel A3 (see Fig. 3) represented in Fig. 17 as a function of the RMS acceleration and the 10-min mean wind speed.

The regression curve of the RMS response, otherwise known as buffeting curve, is generally expressed as:

$a_{R M S}=c_{1} \bar{U}^{c_{2}}$

where $a_{R M S}$ is the 10-min RMS value of the acceleration response, $\bar{U}$ is the 10 -min mean wind speed, and $c_{1}$ and $c_{2}$ are the curve fitting parameters.

A non-linear least-squares curve fitting was applied to the field measurements of each accelerometer for the three prevalent directions. Table 2 lists the resulting $c_{1}$ and $c_{2}$ parameters.
6.2. Influence of temperature and mean wind speed on natural frequencies

The modal parameters identified by the dynamic monitoring system reflect the influence of environmental and operational factors. Of the various possible factors, temperature and wind have been identified as the ones that have a dominant role. To understand the corresponding effect, it is noted that temperature increase leads to a decrease of the elasticity modulus of the concrete of the slabs, to an increase of the cables length, and so, to an increment of the sag of the cables and reduction of tension, simultaneously with an increase of the slab bending stiffness. The combination of the two effects may result in increasing or 


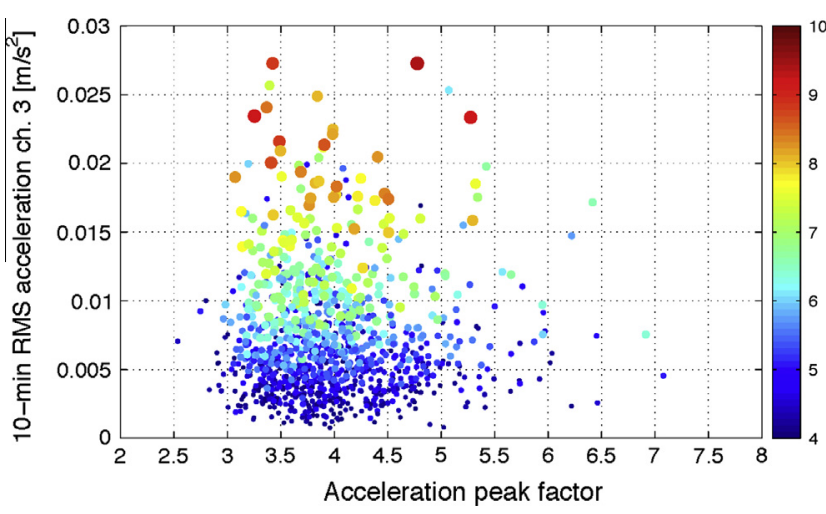

Fig. 17. Variation of peak factor with RMS acceleration at channel A3 and 10-min mean wind speed.

decreasing frequency with temperature for different vibration modes, depending on the relative participation of slab bending and cable deformation. As for wind effects, positive incidence typical from northern directions leads to a sag reduction, with consequent reduction of the cable tension and, possibly, frequency, while negative incidence, typical from southern directions has an opposite effect.

In order to analyse the dependence between the mean wind speed, the ambient temperature variation and the value of the identified natural frequencies, the Pearson correlation coefficients were computed.
Table 3 summarises the measures of correlation found between the identified natural frequencies and the mean wind speed and temperature.

It is evident from the analysis of Table 3 that, apart from modes 3 and 4 , the value of natural frequencies tends to vary inversely with both the mean wind speed and the mean temperature. The correlation with the mean wind speed in modes 3 (Fig. 18(a and d)) and 4 is the smallest observed, with values close to zero, and contrary to the general trend, the value of the natural frequency tends to increase with higher ambient temperatures. This aspect can be observed in Figs. 13(b) and 17. An overall trend for a greater correlation between the natural frequencies and the mean temperature than with the mean wind speed is observed across Table 3. Exceptions are found for mode 6 (Fig. 18(b and e)), where the correlation with mean temperature is approximately zero, and modes 11 (Figs. 18(c and f)) and 12, that show a similar degree of correlation with both variables.

To further investigate the effect of mean wind speed and mean temperature variation on the value of natural frequencies, the following linear regression was applied:

$f_{i}=\beta_{0} \bar{T}+\beta_{1} \bar{U}+\beta_{2}$

where $f_{i}$ is the natural frequency, $\bar{T}$ is the mean temperature, $\bar{U}$ is the mean wind speed, and $\beta_{0}, \beta_{1}$ and $\beta_{2}$ are fitting parameters. Table 4 lists the regression parameters and the $R^{2}$ value for each mode.

The regression results found corroborate the trends obtained from the correlation coefficient analysis. Furthermore, parameters $\beta_{0}$ and $\beta_{1}$ give a measure of how the natural frequencies change

Table 3

Pearson correlation coefficients between the natural frequency values and the mean wind speed and mean sonic temperature.

\begin{tabular}{|c|c|c|c|c|c|c|c|c|c|c|c|c|}
\hline & \multicolumn{12}{|c|}{ Natural frequency of mode: } \\
\hline & 1 & 2 & 3 & 4 & 5 & 6 & 7 & 8 & 9 & 10 & 11 & 12 \\
\hline $\bar{U}$ & -0.28 & -0.27 & 0.03 & 0.08 & -0.26 & -0.34 & -0.37 & -0.30 & -0.21 & -0.18 & -0.46 & -0.38 \\
\hline $\bar{T}$ & -0.60 & -0.69 & 0.76 & 0.62 & -0.36 & -0.04 & -0.44 & -0.59 & -0.66 & -0.61 & -0.41 & -0.34 \\
\hline
\end{tabular}

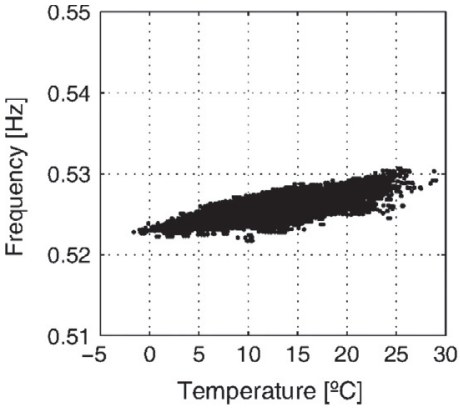

(a) Mode 3

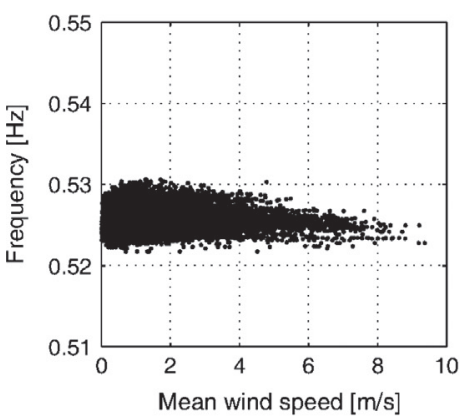

(d) Mode 3

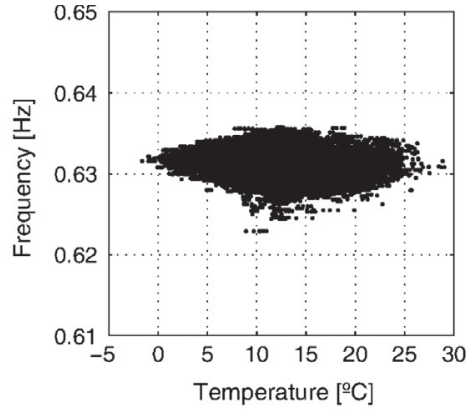

(b) Mode 6

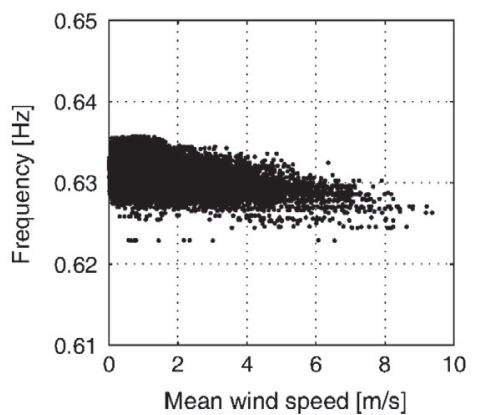

(e) Mode 6

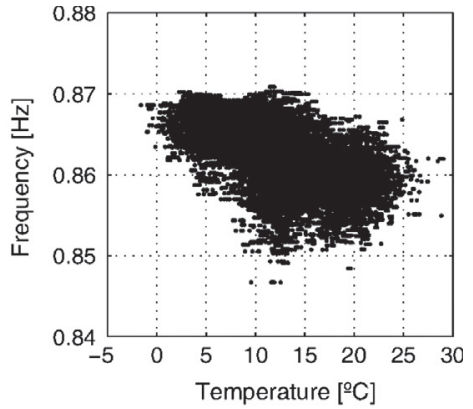

(c) Mode 11

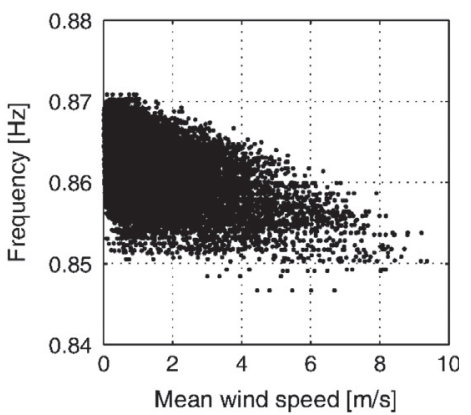

(f) Mode 11

Fig. 18. Correlation between the identified natural frequencies and: (a-c) mean sonic temperature; and (c-e) mean wind speed; for modes 3,6 and 11 . 
Table 4

Regression parameters between the identified natural frequencies, the mean sonic temperature and the mean wind speed measured by WS1.

\begin{tabular}{clcll}
\hline Mode & $\beta_{0}\left(\times 10^{-4} \mathrm{~Hz}^{\circ} \mathrm{C}^{-1}\right)$ & $\beta_{1}\left(\times 10^{-4} \mathrm{~Hz}(\mathrm{~m} / \mathrm{s})^{-1}\right)$ & $\beta_{2}(\mathrm{~Hz})$ & $R^{2}$ \\
\hline 1 & -0.65 & -0.99 & 0.275 & 0.53 \\
2 & -1.19 & -1.47 & 0.292 & 0.64 \\
3 & 2.08 & -0.49 & 0.523 & 0.58 \\
4 & 1.35 & 0.46 & 0.540 & 0.30 \\
5 & -2.51 & -7.00 & 0.554 & 0.19 \\
6 & -0.53 & -4.46 & 0.632 & 0.14 \\
7 & -0.93 & -3.38 & 0.654 & 0.35 \\
8 & -2.17 & -5.29 & 0.683 & 0.14 \\
9 & -2.48 & -1.87 & 0.699 & 0.48 \\
10 & -3.54 & -2.23 & 0.736 & 0.35 \\
11 & -3.62 & -13.25 & 0.868 & 0.45 \\
12 & -2.71 & -17.12 & 1.007 & 0.29 \\
\hline
\end{tabular}

with mean temperature and mean wind speed, respectively. It is worth noting that the natural frequencies of modes 10 and 11 show a greater sensibility to temperature change, while values from modes 1 and 6 are the least sensitive to this variable. Frequencies from modes 11 and 12 show higher variations with mean wind speed change. On the other hand, values corresponding to modes 3 and 4 show the smallest influence. It must be stressed that the established correlations are valid within the temperature and wind speed intervals measured.

The coefficient $R^{2}$, that measures the quality of the established correlation, ranges from 0.14 for modes 6 and 8 , indicative of a very poor relationship, to 0.64 for mode 2 , suggesting a stronger dependence on these variables.

\subsection{Influence of the temperature and mean wind speed on damping ratios}

It was previously discussed that the identified damping ratios show a significant scatter, despite the slight evidence of a daily pattern associated with the wind speed and temperature change (Fig. 13(a)). To study the relationship between damping ratios and the mean temperature and mean wind speed, the Pearson correlation coefficients between these variables were calculated. Table 5 summarises the most important results of the correlation analysis. The analysis of this table shows a trend for the identified damping ratios to vary proportionally with both the mean wind speed and the mean temperature, the only exception being the almost null correlation coefficient with temperature of the damping ratio associated with mode 11 . The main conclusion is that for all investigated modes the variation of the damping ratio is more associated with the change of mean wind speed than of mean temperature. For this reason, only the relationship between damping ratios and mean wind speed has been considered in subsequent analyses.

Fig. 19 represents the relation with mean wind speed of the identified damping ratios for modes 1,3 and 9 . The approximately linear relationship observed in the range of measured mean wind speed is common to all identified modes and reflects the wind induced added damping to the total identified damping ratio.

The damping measurements corresponding to periods of very low wind speeds (lower than $2 \mathrm{~m} / \mathrm{s}$ ) were averaged for each mode in order to obtain an estimate of the structural damping $\left(\xi_{\text {structural }}\right)$. In a different approach, least-squares linear fit was applied to the identified damping points associated with mean wind speed higher than $2 \mathrm{~m} / \mathrm{s}$. The constant term of the fitted line provides alternatively an estimate of the structural damping, while the slope parameter expresses the wind induced added damping gradient $\left(\Delta \xi_{\text {aerodynamic }}\right)$ [46]. Table 6 summarises the obtained results for all identified modes and Fig. 19 shows the fitted line and the structural damping values.

A great resemblance for the estimated structural damping values is found across all modes, with a general trend for greater values obtained by the averaging approach at low wind speed. The computed values for wind induced added damping range from $0.015 \%(\mathrm{~m} / \mathrm{s})^{-1}$, for mode 9 , to $0.060 \%(\mathrm{~m} / \mathrm{s})^{-1}$, for mode 11 , and

Table 5

Pearson correlation coefficients between identified damping ratios and the mean wind speed and mean sonic temperature.

\begin{tabular}{|c|c|c|c|c|c|c|c|c|c|c|c|c|}
\hline & \multicolumn{12}{|c|}{ Damping ratio of mode } \\
\hline & 1 & 2 & 3 & 4 & 5 & 6 & 7 & 8 & 9 & 10 & 11 & 12 \\
\hline $\bar{U}$ & 0.49 & 0.48 & 0.46 & 0.41 & 0.34 & 0.36 & 0.40 & 0.50 & 0.37 & 0.43 & 0.35 & 0.46 \\
\hline $\bar{T}$ & 0.17 & 0.18 & 0.17 & 0.13 & 0.27 & 0.19 & 0.13 & 0.18 & 0.14 & 0.21 & -0.05 & 0.27 \\
\hline
\end{tabular}

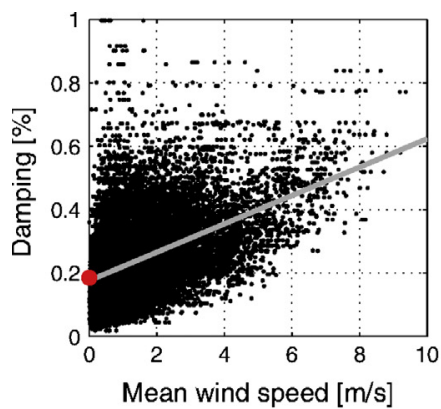

(a) Mode 1

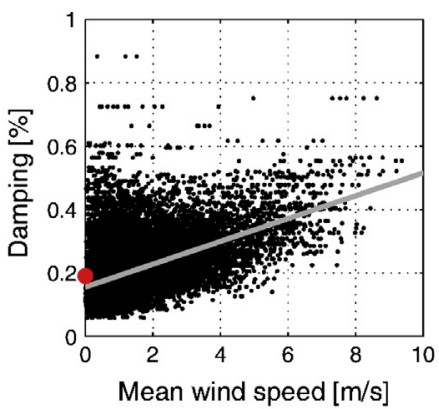

(b) Mode 3

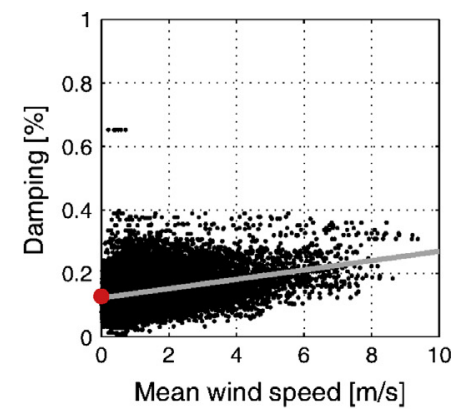

(c) Mode 9

$$
\begin{array}{ll|}
\hline \text { - Field measurements } \\
\text { Fitted } \\
\xi_{\text {structural }}(\mathrm{U}<2 \mathrm{~m} / \mathrm{s})
\end{array}
$$

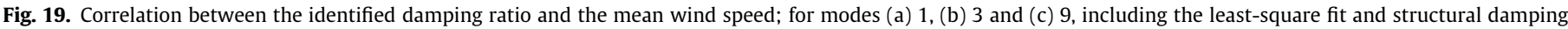
computed from low wind speeds. 
Table 6

Summary of measured damping coefficients.

\begin{tabular}{|c|c|c|c|c|c|c|c|}
\hline \multirow[t]{2}{*}{ Mode } & \multirow{2}{*}{$\begin{array}{l}\xi_{\text {structural }} \\
\bar{U}<2 \mathrm{~m} / \mathrm{s}(\%)\end{array}$} & \multicolumn{3}{|c|}{ Linear regression } & \multirow{2}{*}{$\begin{array}{l}\text { Free vib. } \\
\text { Filter (\%) }\end{array}$} & \multirow{2}{*}{$\begin{array}{l}\text { Free vib. } \\
\text { SSI-COV (\%) }\end{array}$} & \multirow{2}{*}{$\begin{array}{l}\text { Harmonic } \\
\text { Excitation (\%) }\end{array}$} \\
\hline & & $\xi_{\text {structural }}(\%)$ & $\Delta \xi_{\text {aerodynamic }}\left(\%(\mathrm{~m} / \mathrm{s})^{-1}\right)$ & $R^{2}$ & & & \\
\hline 1 & 0.19 & 0.18 & 0.045 & 0.19 & - & 0.29 & 0.28 \\
\hline 2 & 0.16 & 0.13 & 0.048 & 0.24 & - & 0.37 & 0.27 \\
\hline 3 & 0.19 & 0.16 & 0.036 & 0.25 & 0.28 & 0.33 & 0.22 \\
\hline 4 & 0.16 & 0.14 & 0.024 & 0.16 & 0.25 & 0.22 & - \\
\hline 5 & 0.36 & 0.30 & 0.044 & 0.18 & - & 0.44 & - \\
\hline 6 & 0.25 & 0.22 & 0.033 & 0.18 & 0.34 & 0.36 & 0.43 \\
\hline 7 & 0.19 & 0.19 & 0.019 & 0.12 & - & 0.29 & - \\
\hline 8 & 0.14 & 0.11 & 0.030 & 0.26 & - & 0.11 & 0.20 \\
\hline 9 & 0.13 & 0.12 & 0.015 & 0.10 & - & 0.18 & - \\
\hline 10 & 0.13 & 0.11 & 0.023 & 0.21 & 0.20 & 0.18 & - \\
\hline 11 & 0.32 & 0.21 & 0.060 & 0.32 & - & - & - \\
\hline 12 & 0.38 & 0.35 & 0.040 & 0.22 & - & - & - \\
\hline
\end{tabular}

correspond to an average of $20 \%$ of the structural damping per $\mathrm{m} / \mathrm{s}$. The quality of the least-square linear fits is generally low, due to the significant scatter of the identified damping ratios.

Damping ratios for the roof structure have been previously estimated based on forced and free vibration tests [37]. The main results of those tests are shown in Table 6 for comparison with the present estimates. It is observed that the damping ratios identified from forced and free vibration tests are generally greater than the corresponding values obtained under ambient vibration, fact that can be explained by the larger vibration amplitudes associated with the former tests. Nevertheless, structural damping estimates identified in the present study have the same order of magnitude of previous estimates and should be considered good approximations.

\section{Conclusions}

Combining recent developments in terms of sensors, data communicating systems, computational power and identification algorithms, the continuous monitoring program established around the suspension roof of the Braga Stadium has allowed the continuous measurement of wind, temperature and acceleration. The variation of such quantities during a period of 8 months has been investigated, with the purpose of obtaining a characterisation of the wind action based on field tests, establishing correlations with the structural response and finally analysing the influence of wind and temperature on the variation of modal parameters.

The measurement of wind using two sonic anemometers mounted on one of the slabs has permitted the identification of dominant directions, incidences and intensity of the typical wind speed, as well as allowed the characterisation of the intensity of turbulence and the spectral content, for the purpose of future verification of the design wind model.

The measurement of acceleration at 6 points along one of the slabs has allowed the establishment of response correlations with the wind velocity, which will be used as well to verify corresponding information obtained from wind tunnel tests at design stage.

Finally, the continuous identification of modal parameters together with wind and temperature measurements have allowed the investigation of the latter parameters on their variation.

Despite the low wind velocity generally measured and considering the corresponding interval of variation, it has been shown that most natural frequencies are simultaneously influenced by temperature and wind, although temperature generally plays a dominant role, even if having a varying importance according to the vibration mode.

As for damping ratios, whose estimates typically exhibit higher scatter, and again despite the low wind velocity, it was possible to evidence the dominant influence of wind and, using two different approaches, separate the structural from the aerodynamic damping components, with very satisfying agreement, also confirmed by previous estimates based on free and forced vibration methods.

\section{Acknowledgments}

The authors would like to acknowledge: (1) all the supports provided by the Portuguese Foundation for Science and Technology (FCT) to ViBest/FEUP, particularly in the context of Projects "Wind analysis of special structures from full scale measurements" and "DYNAMO_DEMO - Advanced Tools for Dynamic Structural Health Monitoring of Bridges and Special Structures"; (2) the support of AFA Consult (Eng ${ }^{\circ}$ Carlos Quinaz) and Câmara Municipal de Braga; (3) the Ph.D. Scholarship (SFRH/BD/44291/2008) provided by FCT to the third author.

\section{References}

[1] von Kármán T. Progress in the statistical theory of turbulence. Proc Natl Acad Sci USA 1948;34:530-9.

[2] Irwin HPAH, Wardlaw RL. A wind tunnel investigation of a retractable fabric roof for the Montreal Olympic stadium. In: Proceedings of the 5th international conference on wind engineering. Pergamon; 1979. p. 925-938.

[3] Davenport AG. The application of statistical concepts to the wind loading of structures. Proc Inst Civil Eng 1961;19:449-71.

[4] Solari G. Alongwind response estimation: closed form solution. J Struct Div ASCE 1982;108:225-44.

[5] Simiu E, Scanlan RH. Wind effects on structures: fundamental and applications to design. 3rd ed. John Wiley \& Sons; 1996.

[6] Dyrbye C, Hansen SO. Wind loads on structures. John Wiley \& Sons; 1997.

[7] Cremona C, Foucriat J-C. Comportement au Vent des Ponts, Presses de l'École Nationale des Ponts et Chaussées; 2002.

[8] Holmes JD. Wind loading of structures. Spon Press; 2001.

[9] Larsen A, Yeung N, Carter M. Stonecutters Bridge, Hong Kong: wind tunnel tests and studies. Proc ICE - Bridge Eng 2012;165(2):91-104.

[10] Hui MCH, Larsen A, Falbe-Hansen K. Full aeroelastic tests for Stonecutters Bridge. In: IABSE symposium report, IABSE symposium, Shanghai 2004: metropolitan habitats and infrastructure; 2004. p. 72-77(6).

[11] Diana G, Bocciolone M, Colina A, Tosi A, Rochi D. Wind tunnel investigation on Braga Stadium. Final report, Politecnico Milano; 2003.

[12] RWDI. Wind tunnel study of roof wind pressures, Braga Stadium. Report 01$327 ; 2001$.

[13] Hui MCH, Larsen A, Xiang HF. Wind turbulence characteristics study at the Stonecutters Bridge site: part I - mean wind and turbulence intensities. J Wind Eng Ind Aerodynam 2009;97(1):22-36.

[14] Hui MCH, Larsen A, Xiang HF. Wind turbulence characteristics study at the Stonecutters Bridge site: part II - wind power spectra, integral length scales and coherences. J Wind Eng Ind Aerodynam 2009;97(1):48-59.

[15] Wang H, Li A, Hu R. Comparison of ambient vibration response of the Runyang suspension bridge under skew winds with time domain numerical predictions. J Bridge Eng, ASCE July 2011:16(4):513-26.

[16] Peeters B, Couvreur G, Razinkov O, Kündig C, Van der Auweraer H, De Roeck G. Continuous monitoring of the Orsesund Bridge: system and data analysis. Struct Infrastruct Eng 2009;5(5):395-405.

[17] McLamore V, Hart G, Stubbs I. Ambient vibration of two suspension bridges. ASCE J Struct Div 1971;97(ST10):2567-82.

[18] Bietry J, Jan P. Essais Dynamiques du Pont de Normandie. Report of "Mission du Pont de Normandie". EN-D 95.5 C, CSTB; 1995.

[19] Cunha A, Caetano E, Delgado R. Dynamic tests on a large cable-stayed bridge. An efficient approach. J Bridge Eng, ASCE 2001;6(1):54-62. 
[20] Catbas FN, Grimmelsman KA, Aktan AE. Structural identification of the Commodore Barry Bridge. Proc SPIE 2000;3995:84-97.

[21] Brownjohn JMW, Moyo P, Omenzetter P, Lu Y. Assessment of highway bridge upgrading by dynamic testing and finite element model updating. J Bridge Eng, ASCE 2003;8:162-72.

[22] Farrar C, Doebling S, Cornwell P, Straser E. Variability of modal parameters on the Alamosa Canyon Bridge. In: Proc of XV IMAC conference; 1997.

[23] Alampalli S. Influence of in-service environment on modal parameters. In: Proc of 16th int modal analysis conference, Santa Barbara, USA; 1998.

[24] Kramer C, de Smet C, De Roeck G. Z24 bridge damage detection tests. In: Proceedings of IMAC XVII, Kissimmee, Florida; 1999. p. 1023-29.

[25] Wong KY. Instrumentation and health monitoring of cable-supported bridges. Struct Control Health Monit 2004;11:91-124.

[26] Ko JM, Ni YQ. Technology developments in structural health monitoring of large-scale bridges. Eng Struct 2005;27(12):1715-25.

[27] FIB. Monitoring and safety evaluation of existing concrete structures. FIB Bulletin 22; 2003.

[28] Magalhães F, Cunha A, Caetano E. Vibration based structural health monitoring of an arch bridge: from automated OMA to damage detection. Mech Syst Signal Process 2012;28:212-28 [special issue on interdisciplinary and integration aspects in structural health monitoring].

[29] Cunha A, Caetano E, Magalhães F, Moutinho C. Recent perspectives in dynamic testing and monitoring of bridges. Struct Control Health Monit 2013;20(6): 853-77.

[30] Furtado R, Quinaz C, Bastos R. New Braga Municipal Stadium, Braga. Struct Eng Int 2005;2:72-6

[31] Caetano E. Numerical modeling of the structural behaviour of the new Braga Stadium roof, Porto, Portugal. Technical report; 2001.

[32] Caetano E, Cunha Á, Magalhães F. Numerical and experimental studies of the Braga Sports Stadium suspended roof. Struct Infrastruct Eng 2010;6(6): 715-24.

[33] Magalhães F, Caetano E, Cunha Á. Operational modal analysis and finite element model correlation of the Braga Stadium suspended roof. Eng Struct 2008;30(6):1688-98.
[34] Majowiecki M, Cosentino N. Dynamic aspects of the New Braga Stadium large span roof. In: Proceedings of IASS symposium; 2007.

[35] Magalhães F, Cunha Â, Caetano E. Installation of a continuous dynamic monitoring system at Braga Stadium suspended roof: initial results from automated modal analysis. In: EVACES 2009, Wroclaw, Poland; 2009.

[36] Martins N, Cardoso A, Caetano E. Development of an observation system based on anemometry to characterize the wind action over a suspension roof. In: YIC2012; 2012.

[37] Magalhães F, Caetano E, Cunha Á. Operational modal analysis of the Braga sports stadium suspended roof. In: IMAC XXIV, St. Louis, MO; 2006.

[38] Kaimal JC, Finnigan JJ. Atmospheric boundary layer flows: their structure and measurement. USA: Oxford University Press; 1994.

[39] Wilczak JM, Oncley SP, Stage SA. Sonic anemometer tilt correction algorithms. Bound-Layer Meteorol 2001;99(1):127-50.

[40] Solari G, Piccardo G. Probabilistic 3-D turbulence modeling for gust buffeting of structures. Probab Eng Mech 2001;16(1):73-86.

[41] Shiau BS, Chen YB. Observation on wind turbulence characteristics and velocity spectra near the ground at the coastal region. J Wind Eng Ind Aerodyn 2002;90(12):1671-81.

[42] Tamura Y, Kareem A, Solari G, Kwok KCS, Holmes JD, Melbourne W. Aspects of the dynamic wind-induced response of structures and codification. Wind Struct 2005;8(4):251-68.

[43] CEN. Eurocode 1: actions on structures - general actions - Part 1-4: wind actions, vol. 3. British Standards Institution; 2005.

[44] Magalhães F, Cunha Á, Caetano E. Online automatic identification of the modal parameters of a long span arch bridge. Mech Syst Signal Process 2009;23(2): 316-29.

[45] Shigehiko S, Nakamura T, Inada F, Kato M. Flow-induced vibrations: classifications and lessons from practical experiences. Elsevier Science; 2008

[46] Macdonald JHG. Separation of the contributions of aerodynamic and structural damping in vibrations of inclined cables. J Wind Eng Ind Aerodyn 2002;90(1): 19-39. 